\title{
Review
}

Ndepana A. Gaya, Victor Charles, Innocent Joseph, Hitler Louis*

\section{A review on $\mathrm{CO}$ oxidation, methanol synthesis, and propylene epoxidation over supported gold catalysts}

https://doi.org/10.1515/cse-2019-0003

received February 6, 2019; accepted June 3, 2019.

\begin{abstract}
The aim of this general review is to give an overview of the reaction pathways involving the transformation of carbon monoxide (CO), methanol synthesis and propylene epoxidation using gold (Au) and gold supported clusters. Over the catalyst system of Nano-gold $\left(\mathrm{Au} / \mathrm{SiO}_{2}\right)$, the process of methane to methanol was also highlighted. A reaction mechanism proposed, indicated that molecular oxygen was consumed in the oxidation-reduction cycle. Consequently, methane oxidation to methanol can be achieved as a green chemical process. The system can also be used in other green chemical processes of liquid phase or gas phase oxidations. Methanol is expected to be a potential solution to the partial deployment of fossil source-based economies. Moreover, it is a recognized energy carrier that is better than other alternatives in terms of transportation, storage and reuse. New or improved catalysts for methanol production are likely to be discovered in the near future.
\end{abstract}

Keywords: Gold; gold-supported oxide; clusters; oxidation; methanol synthesis; epoxidation.

\section{Introduction}

For some time, Gold $(\mathrm{Au})$ was regarded as a poorly active catalyst. Theoretical findings newly describe reason

\footnotetext{
*Corresponding author: Hitler Louis, National Centre for Nanoscience and Technology, 100190 Beijing, China, E-mail: louismuzong@gmail.cm

Ndepana A. Gaya, Department of Chemistry, Modibbo Adama University of Technology, Nigeria

Victor Charles, Institute of Process Engineering, Chinese Academy of Sciences, 100190, Beijing, China

Innocent Joseph, National Centre for Nanoscience and Technology, 100190 Beijing, China
}

behind the glossiness of $\mathrm{Au}$ surface when adsorbed by hydrogen $\left(\mathrm{H}_{2}\right)$ [1]. Nonetheless, by depositing $\mathrm{Au}$ nanoparticles on metal oxides through co-precipitation as well as deposition-precipitation (DP) techniques, the $\mathrm{Au}$ nanoparticles (NPs) displayed a high catalytic activity for oxidation of carbon monoxide (CO) at a temperature as low as 200K [2,3]. Numerous scientists and related field where motivated by this findings to probe Au catalysis several years back (1990s). The new shift in the cost of Au (US\$9/g) in commercial system with regards to Palladium/Platinum (Pd/Pt) (US\$ 14/g), which can propel market improvement of $\mathrm{Au}$ based catalysts along with economic advantage. Fig. 1 shows a reasonable increase in the annual number of articles in research that are related to catalysis of $\mathrm{Au}$ in previous decade especially very rapidly from 1997. A citation database service, "The Web of Science”, provided by Institute for Scientific Information (ISI, http://www. isinet.com/isi), has been used to search through key words such as 'Au', 'catalysis', 'catalyst(s)', 'catalytic(al), 'catalytically' together with verb conjugations such as, 'catalyze/catalyse', electrocatalysis, photocatalysis, autocatalysis all inclusive. The articles that contain at least one of these words in the title, abstract and key word lists are automatically counted in the numbers, which therefore include a few research works that do not really cover Au catalysis.

$\mathrm{Au}$ Nano particles display good reactivity in $\mathrm{CO}$ oxidation at low temperature [4], which results to the utilization of $\mathrm{Au}$ /oxide accompanied by inverse oxide/ $\mathrm{Au}$ catalysts studied widely in dissimilar reactions [5]. The mechanism of metal oxides support for Au catalyst in reactions involving the oxidation of $\mathrm{CO}$ is quite complex (as established by some current studies on catalyst), this is due to a lot of factors that controls the reaction of the Au-based catalyst, similar to the low-coordinated sites of a very tiny particles surface that are present [6], the nature of the support [7], the technique used to produce the catalyst [8], and the reaction conditions, etc. Even though the complexity of the nature of interface between $\mathrm{Au}$ and 


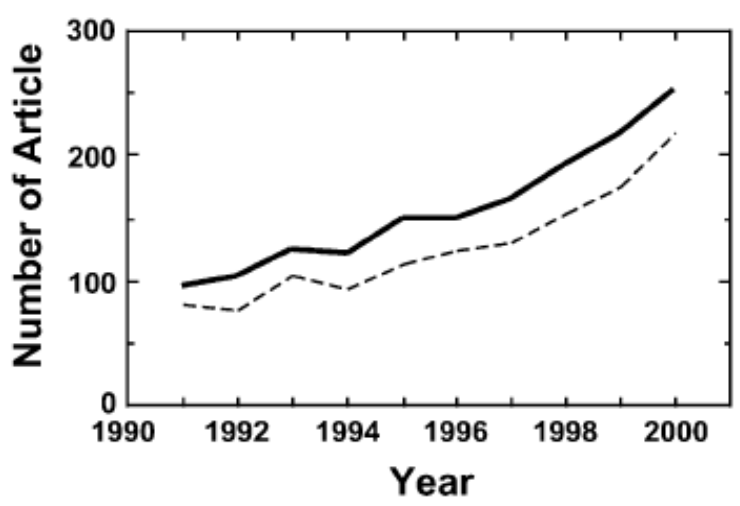

Figure 1: The numbers of articles concerning Au catalysts in the last decade. Fundamental/broaden search are represented by the dots/ thick lines separately

its support is not well understood, yet, it can have effect on the nature of active sites in reactions related to oxidation of CO [9]. Current advances regarding growth in the field of $\mathrm{Au}$ catalysts probing oxidation of $\mathrm{CO}$ are presented in few excellent reviews $[7,10]$. Au catalysts supported on metal oxides, like Iron oxide $\left(\mathrm{Fe}_{2} \mathrm{O}_{3}\right)$, Cerium oxide $\left(\mathrm{CeO}_{2)}\right.$, and Titanium oxide $\left(\mathrm{TiO}_{2}\right)$ were examined because of their direct participation in reaction mechanism of CO oxidation accompanied by their ability to adsorb or store oxygen $\left(\mathrm{O}_{2}\right)$ at low temperatures, lattice $\mathrm{O}_{2}$ mobility, stabilization of $\mathrm{Au}$ nanoparticles through means of inducing stronger interaction between metal-support, and/or to generate ionic Au species [11]. However, sadly, actual surface area of Au-based catalysts with reducible oxides as support is small compared to other catalyst with mixed oxides as support [12]. The activity of Au catalyst is highly influenced by [13, 14]: (i) The size and shape of $\mathrm{Au}$ particles; (ii) the methods used to synthesize the catalyst (iii) The nature of support materials (iv) The reaction taking place at the interface between $\mathrm{Au}$ and the support (v) And the oxidation state(s) of Au in the synthesized catalysts as reported by many studies. As a result, diverse process of absorbing nanoparticles of Au on distinct metal oxides were demonstrated by various findings, these includes; oxides of $\mathrm{Ti}, \mathrm{Fe}, \mathrm{Ce}, \mathrm{Mg}$ and $\mathrm{Si}$ etc. as already reported by different research groups to overcome this problem [15]. Depending on the type of support, Au-based catalysts are synthesized through the following methods: Deposition-precipitation method, Co-precipitation, Colloidal dispersion and liquid-phase grafting method etc as previously mentioned. But deposition-precipitation (DP) happens to be the most widespread approach that is generally employed in the synthesis of Au-based catalyst with metal oxides as it support with elevated Isoelectric point (IEP), which is illustrated in the synthesis of the oxides of $\mathrm{Ti}, \mathrm{Fe}, \mathrm{Al}$ and $\mathrm{Ce}$ etc. using depositionprecipitation method [16]. Recently, much attention has been drawn towards Au catalyst because of its prospective usefulness in quite a number of reactions which are vital to environment as well as industry. Current study points out latest advances on catalysis research of $\mathrm{Au}$. CO oxidation mechanistic topics are summarized, focusing on $\mathrm{Au} / \mathrm{TiO}_{2}$, $\mathrm{Au} / \mathrm{CeO}_{2}$ and $\mathrm{Au} / \mathrm{SiO}_{2}$ together with other advances that specialize on $\mathrm{Au}$ and catalytic reactions of $\mathrm{Au}$ supported Nano-clusters [5]. Furthermore, recent developments are presented in propylene epoxidation and synthesis of methanol $\left(\mathrm{CH}_{3} \mathrm{OH}\right)$. Perimeter interface between $\mathrm{Au}$ particles as well as the support plays a vital role as a unique reaction site for reactants adsorbed separately on both $\mathrm{Au}$ and the support respectively.

Although it is a general agreement that the role of support in Au-supported catalyst is given thus; to stabilize active Au particles, the support material interaction with $\mathrm{Au}$ particles is vital in catalytic activity [17]. Given an instance; oxidation of CO, exceptionally high activities have been described for reducible metal oxide support such as $\mathrm{TiO}_{2}, \mathrm{Fe}_{2} \mathrm{O}_{3}, \mathrm{CeO}_{2}$ suggesting that the support supplies oxygen to form active oxide Au sites [18], it was further suggested that the sites on Au-support interface are responsible for CO oxidation activity [19]. With these report in mind, assumption can be made to show that the most vital factor for the formation of the activity of Au catalyst which includes study of the oxidation of $\mathrm{CO}$ in relation to Au catalyst support on metal oxide compare to other numerous supports with different properties is the contact structure. Theoretical findings contribute to quite a number of reviews regarding Au catalytic system which is now common [20]. Shell closing provides the basis for the synthesis of Nano catalyst by describing how ligand protected clusters are produced and the reaction of clusters with definite sizes. Currently, structures like planar model are used to examine $\mathrm{Au}$ technique along with understanding it surface structures [21]. Electron spectroscopy (ES), High-resolution electron loss spectroscopy (HES), infrared spectroscopy (IR), small angle X-ray scattering etc. have been especially useful.

Nano sized Au particles are synthesized conveniently for experimental utilizations in solution and on surfaces. Lately, the most widespread approach of obtaining supported Au catalysts is to use supports (metal-oxides). Heterogeneous catalysis by $\mathrm{Au}$ has improved so greatly, $\mathrm{Au}$ has a reasonable catalytic activity during oxidation of CO especially with small intensity of temperature as expressed by Haruta in his previous work especially when this catalyst is spread on base metal oxide with nanoparticles as small as $5 \mathrm{~nm}$ in size. Same activity range 
is displayed by this catalyst in a broad reaction pattern which is most notable in oxygen molecule reactions. Highly dispersed Au nanoparticles support on transitionmetal oxides can catalyze low-temperature oxidation of molecular CO Efficiently. Several factors control the activity of those catalysts, especially size of the metal cluster, the ability of the support to supply oxygen during the reaction, and excess electrons at metal/oxide interface which determines $\mathrm{Au}$ atoms oxidation state. Reducible oxides represent very active catalytic supports, and among them are $\mathrm{TiO}_{2}, \mathrm{SiO}_{2}$, and $\mathrm{CeO}_{2}$ among others as reported in this work [22].

There are various reports on Au NPs supported on different oxides, a few of these reports are explained in this review which gives an account on the selectivity and activity of $\mathrm{Au}$ catalyst and some of their reaction mechanisms in the presence of Au NPs etc. Sandoval A. et al work on $\mathrm{Au}$ NPs supported on various oxides such as $\mathrm{Al}_{2} \mathrm{O}_{3}, \mathrm{SiO}_{2}, \mathrm{TiO}_{2}$ and $\mathrm{CeO}_{2}$ (reducible and non-reducible oxides) as catalysts for the WGS reaction. Their report shows a very high activity displayed by these catalysts when $\mathrm{Au}$ is supported on $\mathrm{TiO}_{2}$ and $\mathrm{CeO}_{2}$ as support that is, $\mathrm{Au} / \mathrm{TiO}_{2}$ and $\mathrm{Au} / \mathrm{CeO}_{2}$ shows higher activity than when $\mathrm{Au}$ is supported on $\mathrm{SiO}_{2}$ (that is $\mathrm{Au} / \mathrm{SiO}_{2}$ ), in other words, the reducible oxides $\left(\mathrm{TiO}_{2}\right.$ and $\left.\mathrm{CeO}_{2}\right)$ exhibit higher catalytic activity than the non-reducible oxides $\left(\mathrm{SiO}_{2}\right.$ and $\left.\mathrm{Al}_{2} \mathrm{O}_{3}\right)$ at temperature below $200^{\circ} \mathrm{C}$. The catalytic activity is in this order; $\mathrm{TiO} 2>\mathrm{CeO} 2>>\mathrm{Al} 2 \mathrm{O} 3 \gg>>\mathrm{SiO} 2$. Based on this report, reducible oxides are catalytically activity compared with non-reducible oxides. [23]

Another report is based on the work of Masoud N. et al, they compare the stability of $\mathrm{Au} / \mathrm{SiO} 2$ with that of $\mathrm{Au} / \mathrm{TiO} 2$ catalyst for the selective hydrogenation of butadiene, they give a report on the activity, selectivity, and stability of 2-4 $\mathrm{nm} \mathrm{Au} \mathrm{NPs} \mathrm{catalysts,} \mathrm{supported} \mathrm{on} \mathrm{either} \mathrm{TiO}_{2}$ or $\mathrm{SiO}_{2}$, for the hydrogenation of $0.3 \%$ butadiene in the presence of $30 \%$ propene. They were able to compared the stability of the Au catalysts because they were prepared using same approach but on different supports. At full conversion of butadiene, only $0.1 \%$ of the propene was converted for both supported catalysts, demonstrating their high selectivity. A steady loss of activity was shown by $\mathrm{TiO}_{2}$ supported catalysts, which was recovered by heating in air. According to this report, it was shown that the deactivation was not caused by significant metal particle growth or the strong interaction between the metal-support, but instead, it is related to the deposition of carbonaceous species under reaction conditions. In contrast, all the $\mathrm{SiO}_{2}$ supported catalysts were highly stable, with very limited formation of carbonaceous deposits. It shows that $\mathrm{SiO}_{2}$ supported catalysts, despite their 2-3 times lower initial activities, clearly outperform $\mathrm{TiO}_{2}$ supported catalysts within a day of run time. The report from this work shows that, $\mathrm{SiO}_{2}$ support (being a reducible oxides) is highly stable with very limited formation of carbonaceous deposit, despite it lower activity when compared with a reducible $\mathrm{TiO}_{2}$ (being a reducible oxide) which exhibit low stability. On the basis of stability $\mathrm{SiO} 2$ has higher stability than $\mathrm{TiO}_{2}$, while base on activity $\mathrm{TiO}_{2}$ shows higher activity. [24].

A recent work in 2018 reported by Ziyauddin S. et al on Silica-Supported Au Nano catalyst for CO Oxidation, also expressed that the catalytic activity of Au NPs supported on reducible metal oxides such $\mathrm{TiO}_{2}, \mathrm{CeO}_{2}, \mathrm{Fe}_{2} \mathrm{O}_{3}, \mathrm{Co}_{3} \mathrm{O}_{3}$ is very high compared to the activity of $\mathrm{SiO}_{2}$ being a non-reducible oxide, but silica is however an inert, inexpensive, and convenient support that can be shaped into a lot of attractive and varied morphologies. This work also gave a hint on the particle size of the catalyst, Au NPs with dimensions less than $5 \mathrm{~nm}$ were found to be active for a number of oxygen transfer reactions, particularly for low-temperature CO oxidation. Au clusters in the 2-5 nm range shows a very high activity, these Au NPs can have a strong interaction with the support and electron relocation may happen within either direction. Silica-supported $\mathrm{Au}$ Nano catalyst has become a good topic of research for $\mathrm{CO}$ oxidation; although, several challenges lies ahead which requires the improvement of silica-supported gold Nano catalyst filling the main necessities of any catalyst such as easy and low-cost synthesis method, high activity, selectivity, and greater stability at lower temperature. Moreover, the proof of identity for the active gold species is still a challenging job for $\mathrm{CO}$ oxidation reactions catalyzed by gold [25]. Although not much report have been given on $\mathrm{CeO}_{2}$ due to limited work done on $\mathrm{CeO}_{2}$ as a support oxide, yet $\mathrm{CeO}_{2}$ has been reported as a reducible catalyst with a very high catalytic activity for CO oxidation, but more work needs to be done to improve the activity of non-reducible support catalyst especially $\mathrm{SiO} 2$ been the cheapest, more inert and more convenient support capable of being shaped into different morphology. There is more report on the $\mathrm{Au} / \mathrm{TiO} 2$ and $\mathrm{Au} / \mathrm{SiO} 2$ catalyst.

Jürgen Behm and Daniel Widmann work on active oxygen on $\mathrm{Au} / \mathrm{TiO}_{2}$ catalyst, and gave account on the reaction mechanism of $\mathrm{Au} / \mathrm{TiO}_{2}$ and also present an important step towards the understanding of the mechanism of $\mathrm{CO}$ oxidation reaction on oxide-supported $\mathrm{Au}$ catalysts in general. Their report shows that the active oxygen for $\mathrm{CO}$ oxidation on $\mathrm{Au} / \mathrm{TiO}_{2}$ catalyst is a highly stable oxygen species, whose formation is facile and hardly activated and they proposed the species to be surface lattice oxygen at the perimeter of $\mathrm{Au} / \mathrm{TiO}_{2}$ interface that is activated by the presence of $\mathrm{Au}$ NPs. 
They were able to draw some conclusion on the nature of the active oxygen from the experimental result, thus; the active oxygen species exhibit high stability that is compatible with molecularly adsorbed oxygen. And they therefore, propose that the active oxygen species is an atomic species, Au NPs have two roles in the CO oxidation reaction: First, they accumulate adsorbed $\mathrm{CO}$, and second, they activate surface lattice oxygen at the Au-TiO2 perimeter sites. In the absence of Au NPs, surface oxygen is not reactive under "normal" reaction conditions. The above conclusion results in a mechanism for $\mathrm{CO}$ oxidation on $\mathrm{Au} / \mathrm{TiO}_{2}$ catalyst at less than $80^{\circ} \mathrm{C}$ demonstrated in the below figure. And involves: CO adsorption on Au NPs, reaction with activated surface lattice oxygen species at the perimeter of the Au-TiO2 interface (interface sites), and replenishment of these sites by dissociative adsorption of $\mathrm{O} 2$ at them.

Rodolfo Zanell et al gave a report few years back on the methods for preparation of $\mathrm{Au}$ on support oxide, they prepare $\mathrm{Au} / \mathrm{TiO} 2$ using different methods; Deposition-precipitation with $\mathrm{NaOH}$, Incipient Wetness Impregnation, Anion Adsorption, Cation Adsorption, Deposition-Precipitation with Urea. Using TEM they obtained the image of the calcined sample. Comparison of the results obtained by DP $\mathrm{NaOH}$ and DP urea shows that the DP urea is a promising method of preparation. According to the report on this work, DP by Urea will serve a better option than DP by $\mathrm{NaOH}$. DP method in general is more advantageous than the other methods mentioned [27]. Although, DP method is the most commonly used approach for metal oxide catalyst support preparation, a recent report on the method of preparation of support metal catalyst as employed by different research was demonstrated by Bahareh A. et al. in their work, they compare the efficacy of the various methods to synthesize supported metal catalysts, they surveyed over 1500 literature articles from the past 3 years. They employed Pt catalysts over $\left(\mathrm{SiO}_{2}\right),\left(\mathrm{Al}_{2} \mathrm{O}_{3}\right),\left(\mathrm{TiO}_{2}\right)$, and carbon (C) supports as examples. They gave a report on strong electrostatic adsorption (SEA) method, it latest version and charge-enhanced dry impregnation (CEDI) method. They compared and contrast these methods to those most prevalent in the literature. SEA and CEDI yield ultrasmall nanoparticles, usually less than $1.5 \mathrm{~nm}$ average particle size, and are simple and scalable, especially CEDI, which is a simple adaptation of common incipient wetness impregnation. These methods can be extended to the synthesis of supported bimetallic nanoparticles with equally efficacious results. The report on this work shows that SEA and CEDI opens a new and a promising approach for support metal catalyst preparation [28].

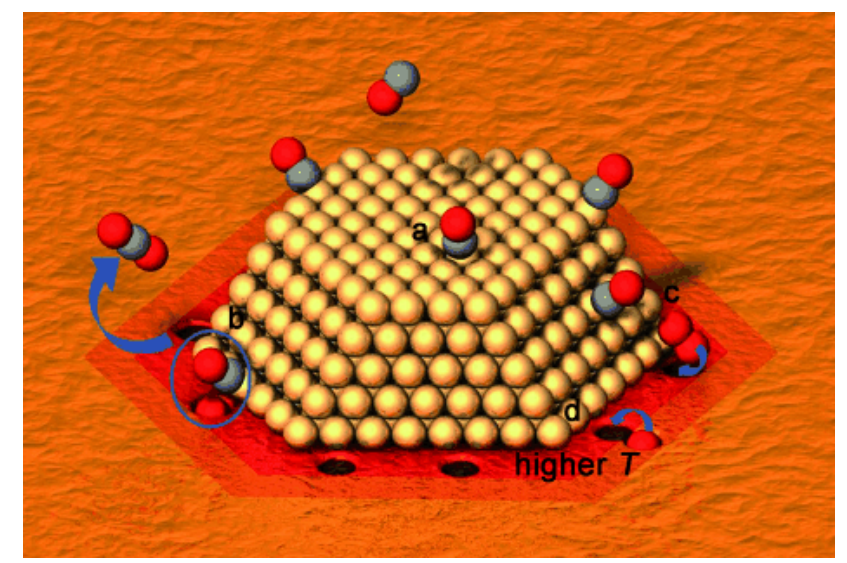

Figure 2: Schematic description of the pathway for $\mathrm{CO}$ oxidation on $\mathrm{Au} / \mathrm{TiO} 2$ catalysts at temperature less than $80^{\circ} \mathrm{C}$ involving the above. [26]

\subsection{CO oxidation}

Oxidation of $\mathrm{CO}$ to Carbon dioxide $\left(\mathrm{CO}_{2}\right)$ has drawn much attention in $\mathrm{Au}$ catalyst research especially at low temperature. Oxides of Nickel (Ni), Cobalt (Co), and Iron $(\mathrm{Fe})$ have been used to support Au during early discovery of Au catalyst activity for $\mathrm{CO}$ oxidation. [29], previously, several studies was carried out on $\mathrm{Au}$ catalyst over different support, however, these supports are independently inactive, but generate reasonable activity for oxidation of $\mathrm{CO}$ when combined together [30]. Numerous elements like; size or proportion of Au catalyst, type and nature of the support, production technique, all influence the catalyst [31]. Some literature reports that the activity of $\mathrm{CO}$ oxidation results from the distinction in $\mathrm{Au}$ [32], while others reports that the active sites results from ionic $\mathrm{Au}$ [33]. While other researchers maintain that catalyst activity is necessary due to both ionic/metallic $\mathrm{Au}$ altogether [34]. CO Oxidation is a typical reaction in which $\mathrm{Au}$ catalysts are extraordinarily active at room temperature, also, much more active compare to other noble metal catalysts at temperatures below 400 Kelvin. A great deal of effort is invested towards developing active catalysts for elimination of trace CO via oxidation. Previously, supported $\mathrm{Pt} / \mathrm{Pd}$ catalysts were extensively probed for reaction involving $\mathrm{CO}$ oxidation. Haruta et al in their latest report described the reason for the high catalytic activity of $\mathrm{Au}$ in $\mathrm{CO}$ oxidation to be as a result of it high spreading. Early work of Haruta/co-workers [T.V. Choudhary et al] motivates many researchers in $\mathrm{Au}$ catalyst research field, hence this result to quite a number of articles touching various angles of $\mathrm{Au}$ catalysts, it reactions and use in the oxidation of $\mathrm{CO}$ [35]. 


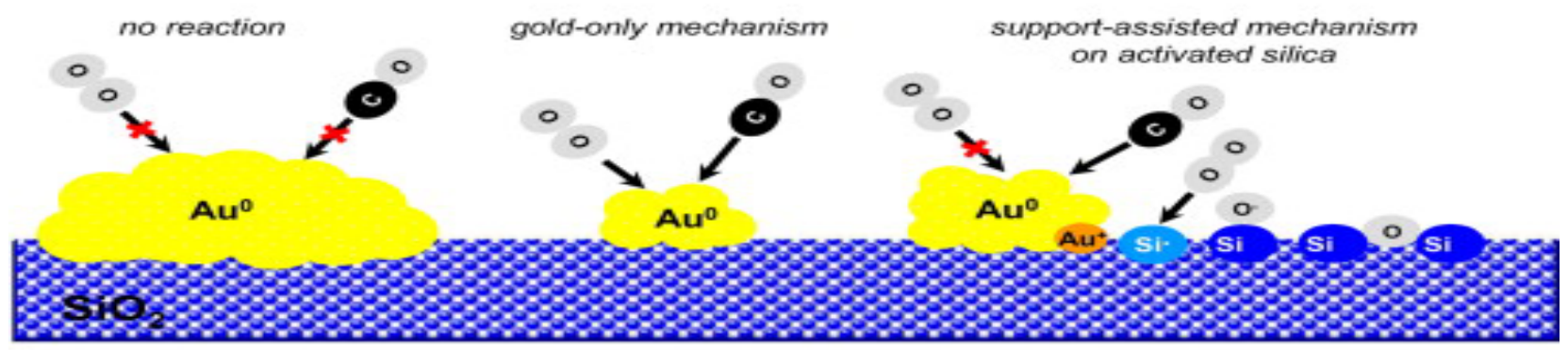

Figure 3:.Schematic representation of oxidation of $\mathrm{CO}$ on gold nanoparticles

Haruta report Au Nano particles (NPs) as very active for oxidation of CO [36]. The two main applications of catalyst based on $\mathrm{Au}$-nanoparticles for oxidation reactions of $\mathrm{CO}$ are: (i) The oxidation of $\mathrm{CO}$ in catalytic exhausts: cold start of engine is accountable for about $80 \%$ of pollution caused by powered vehicles also a big cause of pollution in the air. Au NPs play a vital role to reduce pollution emanating from vehicle exhaust. (ii) Hydrogen Purification for application in fuel cell: CO formed in reforming of methanol adversely affects Pt electrodes of fuel cell. Nanoparticles of gold have the capacity to keep down contamination of Pt anodes caused by CO. Au Nano particles supported on transition metal oxides serve as active catalysts for oxidation reactions at low temperatures [37]. The smaller the size of Au particles, the more reactive they are, and verse vice. As a result of the less activeness of exposed $\mathrm{Au}$, the vitality of oxide support cannot be over emphasized. Incomplete movement of electrons can exist between metal/support from weak center. Because of this, more charge density will be achieved by the cluster thereby triggering the bond connecting molecules of oxygen adsorbed on the surface of the metal cluster [38]. Activation weakens oxygen to oxygen (O-O) bond hence, lowers the barrier so that reaction can occur with $\mathrm{CO}$ followed by subsequent $\mathrm{CO}_{2}$ formation [39]. $\mathrm{CO}$ oxidation mechanism of $\mathrm{Au}$ is affected by several factors such as $\mathrm{Au}$ oxidation state, effect of quantum size, [40] support induced strain [41] etc.

Factors listed above points out the significance of nanoparticles of $\mathrm{Au}$ in $\mathrm{CO}$ oxidation. But the most vital points are

(i) How to allocate shape/size to the real samples shown

(ii) Difficulty in picturing nanoparticles with size smaller than one nanometer

(iii) Activity of given catalyst can be exhibited by some few nanoparticles alone
In last decade, it was expressed that the existence of bilayer clusters align with the remarkable activity of catalyst for carbon monoxide, especially those clusters having just ten $\mathrm{Au}$ atoms whose diameter is half of one [42]. This further indicates that the structure of bilayer Au to be an evaluative property of nanoparticles of Au catalyst that is active, but have low coordinated area, particle support, effects of the movement of charge, and quantum size effects. Several proposed mechanisms exist for reaction involving oxidation of CO. these are predominantly categorized as; mechanism of nanoparticles of $\mathrm{Au}$ with $\mathrm{CO}$ without support, mechanism of $\mathrm{Au}$ nanoparticles with support [43]. Many factors such as kinetics, study of temperature range, kinetic isotope effect reinforce these mechanisms [44]. Fig.3. is a schematically representation of $\mathrm{CO}$ oxidation mechanism

Figure 4 shows growing trend in some number of publications per year involving oxidation of $\mathrm{CO}$ employing catalysts based on Au. Au catalyst have attracted much attention in the past years leading to numerous paper work in $\mathrm{Au}$ research area especially work that pertains $\mathrm{Au}$ catalyst in quote and $\mathrm{CO}$ oxidation. Showing how vital $\mathrm{Au}$ catalyst process is in heterogeneous catalysis.

\subsection{Epoxidation of Propylene}

The attention of chemical industries and research sector has been drowned over the years towards the characteristic features of $\mathrm{Au}$ catalyst supported on metal oxides [45]. Propylene oxide (PO) is one of the important bulk chemicals, which is used for producing polyurethane and polyols. Catalysts of Au capable of synthesizing propylene oxide in just a phase of reaction with only $\mathrm{H}_{2} \mathrm{O}$ as byproduct have the potentials of taking the place of these approaches. Direct epoxidation of propylene for $\mathrm{Au}$ catalysts involves four important factors. First one is method of preparing catalyst. As evidenced in Fig 5, 


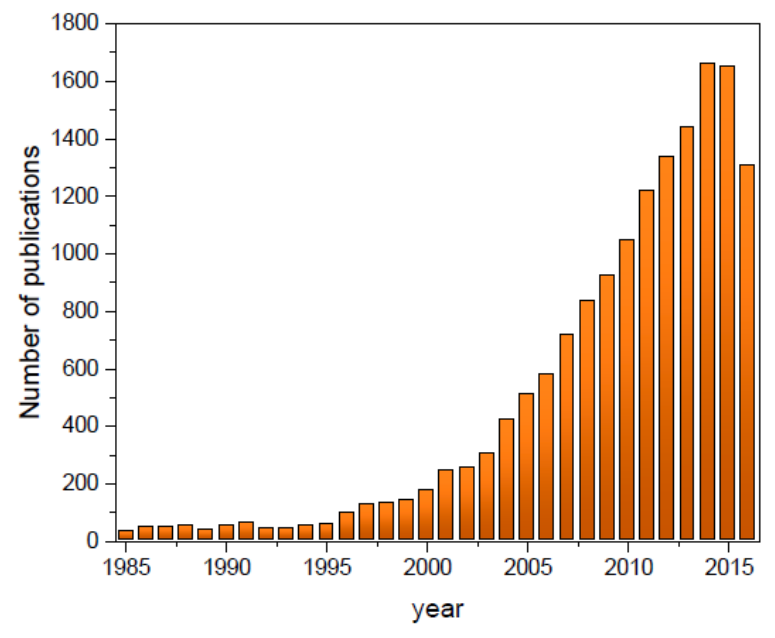

Figure 4: Number of published papers from 1985 in the Scopus Scholar database searching for both gold catalysts / $\mathrm{CO}$ oxidation in quote respectively (September 2016)

deposition-precipitation approach gives good selectivity above $90 \%$ resulting from epoxidation, on the contrary, impregnation fails to give any selectivity instead it oxidizes totally to $\mathrm{CO}_{2}$ and $\mathrm{H}_{2} \mathrm{O}$ [46]. A major dissimilarities in fine structure of the $\mathrm{Au} / \mathrm{TiO}_{2}$ catalysts is that in case of impregnation, a big (several tens nm in diameter) spherical $\mathrm{Au}$ particle is simply mixed with smaller $\mathrm{TiO}_{2}$ particles, whereas in case of deposition-precipitation, small hemispherical $\mathrm{Au}$ particles are actively contacted with $\mathrm{TiO} 2$ particle at their flat planes. The factor responsible for the existence of much interval of circumference interface that is much needed for epoxidation of propylene is the link between particles of $\mathrm{Au}$ with $\mathrm{TiO}_{2}$. Secondly, the appropriate selection of the support materials, among single metal oxides, only $\mathrm{TiO}_{2}$ makes $\mathrm{Au}$ selective for reaction. Furthermore, crystalline structure of $\mathrm{TiO}_{2}$ should be anatase but not rutile and amorphous [46]. Much kind of titanium silicates, titanium supported on silicon oxide, was evaluated as $\mathrm{Au}$ particles support [47-52]. Using Ti placed on $\mathrm{Si}$ as $\mathrm{Au}$ supporting materials, $\mathrm{Au}$ becomes selective to epoxidation at temperature of about 473 kelvin, giving a good conversion rate of close to $5 \%$ [49, 54]. Hydrogen peroxide is formed on the surfaces of $\mathrm{Au}$ which is modified to $\mathrm{OOH}$ on $\mathrm{Ti}^{4+}$ tetrahedrally coordinated in $\mathrm{SiO}_{2}$ matrices to react with propylene as presented by a reaction pathway [53, 54]. Among titanosilicates such like TS-1, Ti- zeolite, Ti-MCM41, Ti-MCM48, having dissimilar pores sizes and structures; Ti-MCM48 is proved to give the leading catalytic achievement [54]. When Ti/Si exceeds $3 / 100$, TiO2 species are assembled to yield $\mathrm{CO}_{2}$ at temperatures above $373 \mathrm{~K}$. This upper limit on Ti/Si ratio is also valid to Ti deposited on $\mathrm{SiO}_{2}$. $\mathrm{SiO}_{2}$ supports were also

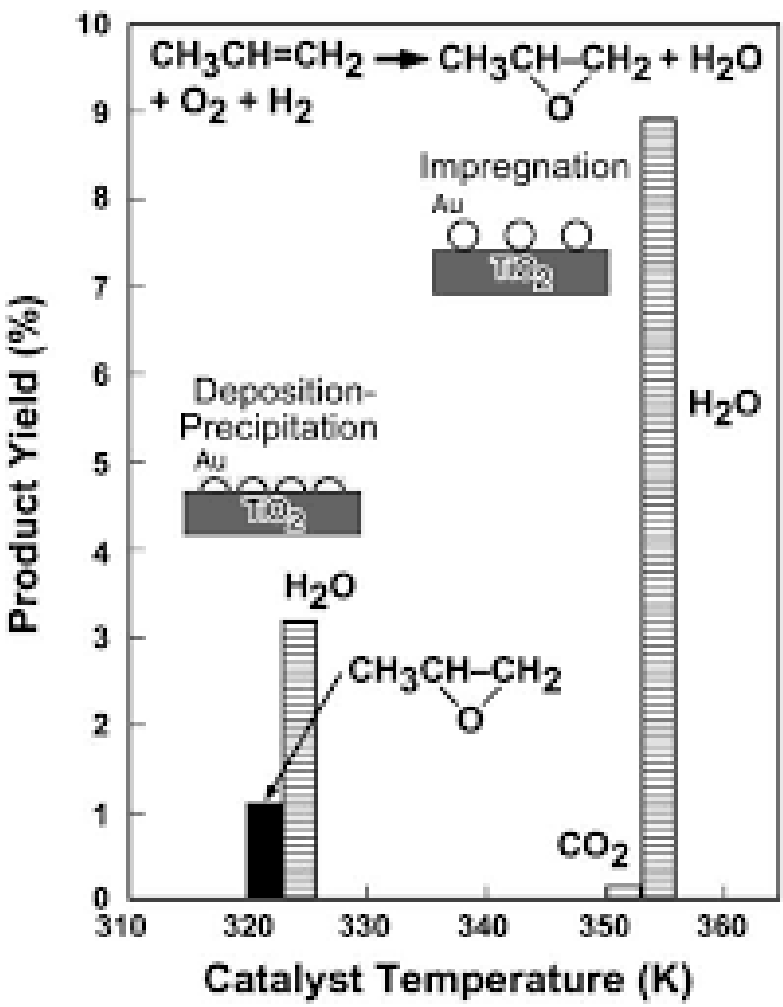

Figure 5: Epoxidation of propylene over $\mathrm{Au} / \mathrm{TiO} 2$ prepared by different methods [46].

tested with a variety of specific surface area from $60 \mathrm{~m}^{2} / \mathrm{g}$ (non-porous) to $800 \mathrm{~m} 2 / \mathrm{g}$ [50]. It appears that there is an optimum pore size, its distribution, and specific surface area. The third one is the size of Au particles. Decrease in size of particles of $\mathrm{Au}$ favors hydrogenation of propylene to propene [55]. This phenomenon has been confirmed by several researchers [53]. The fourth is the additives.

When titanium silicates are used as a support and $\mathrm{Au}$ is deposited by deposition-precipitation, complete washing to remove sodium $(\mathrm{Na})$ and chlorine $(\mathrm{Cl})$ causes the propyolnaldehyde formation instead of $\mathrm{PO}$; however, easy filtration of $\mathrm{Au}$ hydroxide precursor results to selective PO with no more cleaning [47]. This result strongly indicates that alkaline and/or chloride may play an important role in the selective epoxidation. It has been claimed that many alkaline and alkaline earth chlorides work as a good promoter [45, 49]. However, the optimum amount and sites and the mechanistic role have not yet been understood. Successive alteration of the activity of Au catalysts at every hour is one out of the numerous challenges which require solution in the development of direct gas-phase epoxidation of propylene. This is because of acidic/oligomerized species slightly assembled on the surface of catalyst $[53,54]$. Even without any substantial buildup in Au particles size, it is difficult to re-impose the 
early activity entirely regardless of heating temperature to burn off the hydrocarbon residues. Through elementary

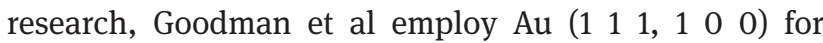
propylene uptake [56]. During the formation of PO, no selectivity was shown by oxygen when it was absorbed onto even surfaces of Au.

\subsection{Methanol Synthesis}

Methanol $\left(\mathrm{CH}_{3} \mathrm{OH}\right)$ is operated broadly as a crucial compound and a basic item in the manufacture of synthetic hydrocarbons, solvent, energy storage medium, and fuel. This status is expected to last in the near future or even improve to the point of making this compound a central participant in worldwide economic landscape. Based on these reasons, every improvement to its manufacturing process, as regards to energy savings, optimization, etc., has potential to promote relevant economic benefits. There are 3 fundamental ways through which $\mathrm{CH}_{3} \mathrm{OH}$ can be made, these include; first syngas production, secondly is to process $\mathrm{CH}_{3} \mathrm{OH}$ while lastly is subsequent detachment. Beneficial idea in postulation of renewable energy which will aid in overcoming inherent variation in supply of renewable energy requires conversion of excess electrical energy storage in form of chemical energy. $\mathrm{CH}_{3} \mathrm{OH}$ being a storage molecule particularly draws attention, due to storage and transportation ease. It is possible to use $\mathrm{CH}_{3} \mathrm{OH}$ as a source of $\mathrm{CO}_{2}$, neutral synthetic fuel or a feedstock for synthesis of a variety of basic material. Nowadays, $\mathrm{CH}_{3} \mathrm{OH}$ is largely obtained from syngas containing $\mathrm{CO}, \mathrm{CO}_{2}$ and $\mathrm{H}_{2}$, which is obtained through catalytic reforming of fossil fuels [57]. Nonetheless, through replacement of fossil fuels as carbon source with anthropogenic $\mathrm{CO}_{2}$ obtained through industrial exhaust or coal power plants [58, 59], for instance, so called "green $\mathrm{CH}_{3} \mathrm{OH}$ " can be obtained $[60,61]$. It is possible to reduce total emission of $\mathrm{CO}_{2}$ through this means [59]. This process was first applied by technical means in 'Emission-to-Liquid' (ETL) technology developed by Carbon Recycling International (CRI), which since 2011 is still in use with a manufacturing record of about 5 mil volume per liters annually [62]. In industrial $\mathrm{CH}_{3} \mathrm{OH}$ production from $\mathrm{CO}_{2}$-enriched syngas typically $\mathrm{Cu}$ / $\mathrm{ZnO}+\mathrm{MeOx}$ catalysts are employed [57]. These have been optimized to a very high performance level under industrial relevant reaction conditions (at elevated temperatures and pressures) because synthesis of industrial $\mathrm{CH}_{3} \mathrm{OH}$ is of immense importance [63]. Based on opinion, it can be regarded as better use for hydrogenation of $\mathrm{CO}_{2}$ for the above operation. On the contrary, manufacture of $\mathrm{CH}_{3} \mathrm{OH}$ from $\mathrm{CO}_{2}$ is ordinarily preceded through unpleasant making of CO through means of reverse water-gas shift reaction [64, 65]. Consequently, apart from the high rate of manufacture of $\mathrm{CH}_{3} \mathrm{OH}$, a principal element which needs to be put into consideration is the selectivity towards manufacture of $\mathrm{CH}_{3} \mathrm{OH}$. Hitherto, the catalytic system studied is very scarce, presenting little or no activeness for manufacture of $\mathrm{CO}$ in $\mathrm{CO}_{2} / \mathrm{H}_{2}$ gas reaction mixtures for manufacture of $\mathrm{CH}_{3} \mathrm{OH}$, for example, differently promoted $\mathrm{Cu}$-based catalysts [66], Au catalyst supported on $3 \mathrm{ZnOZrO}_{2}$ and $\mathrm{Ag}$ catalyst supported on $3 \mathrm{ZnOZrO}{ }_{2}$ respectively [67], carbon nanotubes supported $\mathrm{Pd}-\mathrm{ZnO}$ catalyst [68]. Cu-based catalysts is active when used in reverse water-gas shift (RWGS) reaction between 230/260 1C especially on commercial basis, which led to manufacture of immense quantity of $\mathrm{CO}$ besides methanol, and consequently, low selectivity concerning methanol [68]. It is especially true for Au catalyst support on zinc oxide $\left(\mathrm{ZnO}_{2}\right)$. At present, the much higher price of $\mathrm{Au}$ in comparison with $\mathrm{CO}_{2}$ hydrogenation to $\mathrm{CH}_{3} \mathrm{OH}$ support on Au catalysts is economically not competitive, but these previous reports clearly demonstrated their promising abilities for certain utilization, e.g., small scale processing under dynamic operation conditions, as expected by principles of renewable energy [69]. Discerning the basis of high activity/selectivity of $\mathrm{Au}$ catalyst supported on $\mathrm{ZnO}$ in order to hydrogenate $\mathrm{CO}_{2}$ into $\mathrm{CH}_{3} \mathrm{OH}$ is so captivating especially from the principles of sciences. Here, it is worth stating for both $\mathrm{Au}$ - and $\mathrm{Cu}$-based catalysts the existence of $\mathrm{Zn}$ species seems to be mandatory so as to attain high $\mathrm{CH}_{3} \mathrm{OH}$ formation rates as well as selectivity [70]. This suggests that $\mathrm{Au} / \mathrm{ZnO}$ and $\mathrm{Cu} / \mathrm{ZnO}$ benefit from same effect, namely $\mathrm{ZnO}_{2}$ partial reduction under reaction conditions in highly reductive atmosphere with subsequent migration of $\mathrm{ZnOx}$ surface species on nanoparticles of $\mathrm{Au}$ or Copper (Cu), leading to either formation of AuZn or CuZn alloy, or of $\mathrm{ZnOx}$ shell [71]. Meantime development of $\mathrm{Cu}$ catalyst and the role played by this catalyst in mechanism of oxides of carbon especially $\mathrm{CO}_{2}$ along with $\mathrm{CO}$ hydrogenation reaction to $\mathrm{CH}_{3} \mathrm{OH}$ is being displayed by previous studies [72], but no adequate knowledge corresponding to $\mathrm{Au}$ catalysts supported on $\mathrm{ZnO}$ is available [69]. This kind of outcome can be pictured on the surface of $\mathrm{Au}$ consequently showing the reason why $\mathrm{Au}$ catalyst support on $\mathrm{ZnO}$ has better regards toward the production of $\mathrm{CH}_{3} \mathrm{OH}$ from $\mathrm{CO}_{2}$ and $\mathrm{H}_{2}$ in comparison to other metal oxide support on Au catalysts [69]. Interestingly, Martin et al recently demonstrate the promotion of $\mathrm{Cu}-\mathrm{ZnO}-\mathrm{Al}_{2} \mathrm{O}_{3}$ catalysts for $\mathrm{CH}_{3} \mathrm{OH}$ formation through addition of $\mathrm{Au}$, as explained through stabilization of metallic $\mathrm{CuO}$ species in close region to $\mathrm{ZnOx}$. [66] 


\section{CO oxidation reaction}

Generally speaking, reactions involving oxidation catalysis usually requires use of transition metals such like $\mathrm{Au}, \mathrm{Pd}$, $\mathrm{Pt}$, Ir, Rh,etc. with a metal oxide support such as $\mathrm{TiO}_{2}, \mathrm{SiO}_{2}$, $\mathrm{CeO}_{2}, \mathrm{Fe}_{2} \mathrm{O}_{3}, \mathrm{PtO}_{2}$ etc. Various researchers have worked on the oxidation of CO especially the catalytic activity on metal clusters surfaces [73, 74]. Starting from Langmuir`s work on Pt wires as a noble metal [75]. Such reaction involves simple molecular rearrangements that make it attractive to probe fundamental concepts in catalysis. $\mathrm{CO}$ oxidation also remains some of the good and standard instances showing lack of change in structure; the degree of turnover does not depend on metal dispersion, notwithstanding the fact that unprotected metal atoms are not the same with clusters that possess different size especially in term of structure and coordinative unsaturation

\subsection{Oxidation by $\mathrm{Au} / \mathrm{TiO}_{2}$}

Oxidation of $\mathrm{CO}$ is a distinctive reaction by which $\mathrm{Au}$ catalysts are extraordinarily active at room temperature even much more active than other noble metal catalysts also at temperatures less than 400 Kelvin. Most intensively studied for this reaction is Au support on $\mathrm{TiO}_{2}$. This is because neither $\mathrm{Au}$ nor $\mathrm{TiO}_{2}$ alone is active for oxidation of CO instead their combination generates remarkably high catalytic activity. CO oxidation mechanism is one of the focuses in recent catalysis research work [76-78]. Active site of Au catalysts accommodates particles of Au in metal form indicating $2112 \mathrm{~cm}^{-1}$ absorption band for CO, on the contrary, all manner of $\mathrm{Au}$ oxides showing $2151 \mathrm{~cm}^{-1} \mathrm{Au}$ species absorption band for the $\mathrm{CO}$ mentioned earlier does not account for rise in activity of the catalyst under stable position $[79,80]$. However, smooth surfaces of metallic $\mathrm{Au}$ do not adsorb $\mathrm{CO}$ at room temperature [80], indicating that $\mathrm{CO}$ is adsorbed only at steps, edges, and corner sites. Thus, smaller metallic Au particles are preferable [81]. Au catalyst support on Ti was employed as sample and an encouraging outcome obtained from it based on the work of Goodman et al which is presented in the below figure 5 , the turn over frequency for oxidation of $\mathrm{CO}$ reaches extreme at a diameter of $\mathrm{Au}$ islands of $3.5 \mathrm{~nm}$ (3 atoms thick) at which Au relatively loses its metallic nature [82]. They propose that this change might correspond to high catalytic activity. Since adsorption of $\mathrm{CO}$ on oxide Au sites is inhibited by moisture because of stronger adsorption of $\mathrm{H}_{2} \mathrm{O}$ molecule [83], activity enhancement strongly suggests that metallic Au particles are indispensable for adsorption of CO.

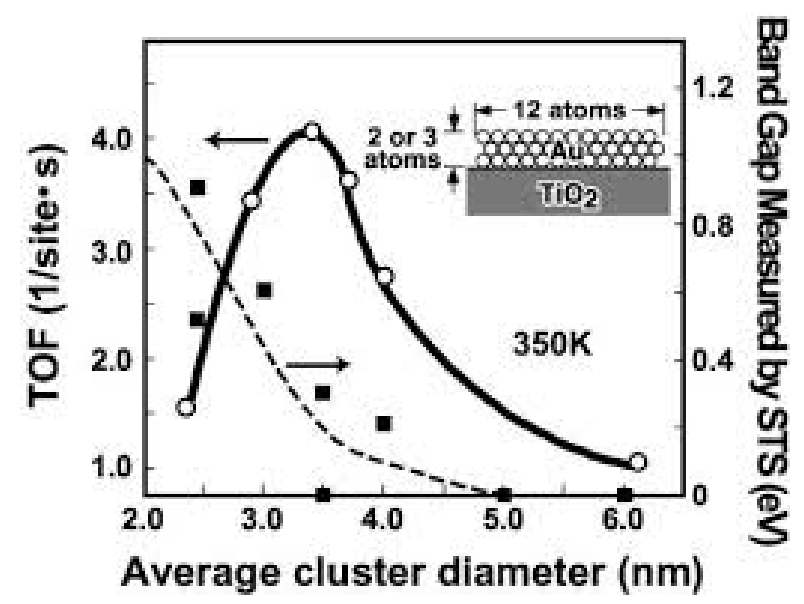

Figure 6: Turn over frequencies/band-gap measured by STM as a function of the diameter of Au islands deposited on TiO2 [76]

The strong contact existing between Au particles and $\mathrm{TiO}_{2}$ support is absolutely necessary for extraordinarily high catalytic activity, because periphery sites are assumed to act as sites for reaction of $\mathrm{CO}$ adsorbed on $\mathrm{Au}$ with oxygen adsorbed on support. Baiker and coworkers make $\mathrm{Au} / \mathrm{TiO}_{2}$ and $\mathrm{Au} / \mathrm{ZrO}_{2}$ by immobilizing $\mathrm{Au}$ colloids of about $2 \mathrm{~nm}$ size on $\mathrm{TiO}_{2}$ and $\mathrm{ZrO}_{2}$ and indicate that strong interfacial contact between $\mathrm{Au}$ and oxides was not necessary [84]. Nevertheless, their observation of enhancement of activity by heating catalyst samples in reactant stream at $423 \mathrm{~K}$ or calcination in argon at $673 \mathrm{~K}$ indicates the contribution of strong contact. It was later reported that $\mathrm{Au} / \mathrm{TiO} 2$ interface was important for oxygen activation [85]. Experiment by S. Tsubota et. al obviously signifies rise in calcination temperature yielding a rise in the activity of catalyst emerging from blending powdery form of $\mathrm{TiO}_{2}$ and $\mathrm{Au}$ colloid, notwithstanding Au particles becomes large [86]. On the contrary, there is rise in the activity of catalyst emerging from great amount of steps, edges, corners of particles of Au relating to CO oxidation; along with how the support relates with the catalyst also contributes to an additional rise in activity at least by one order of magnitude [87]. Overall mechanism of reaction expressing the catalytic operation of Au catalyst supported on $\mathrm{TiO}_{2}$ on vast temperature region was expressed by $\mathrm{M}$. Haruta et al. [88]. Arrhenius plot in Fig. 7 implies three temperature regions with distinct rates of kinetics at visible energies of activation.

Furthermore, the activation energy for the step, corner, sites and edge, is seen almost at $0 \mathrm{~kJ} / \mathrm{mol}$. It means when Au particles are small enough, catalytic activity may be detected at any temperature. Actually unsupported $\mathrm{Au}$ powder (30 $\mathrm{nm}$ in diameter) exhibits measurable activity for oxidation of $\mathrm{CO}$ at 200 Kelvin with noticeable 


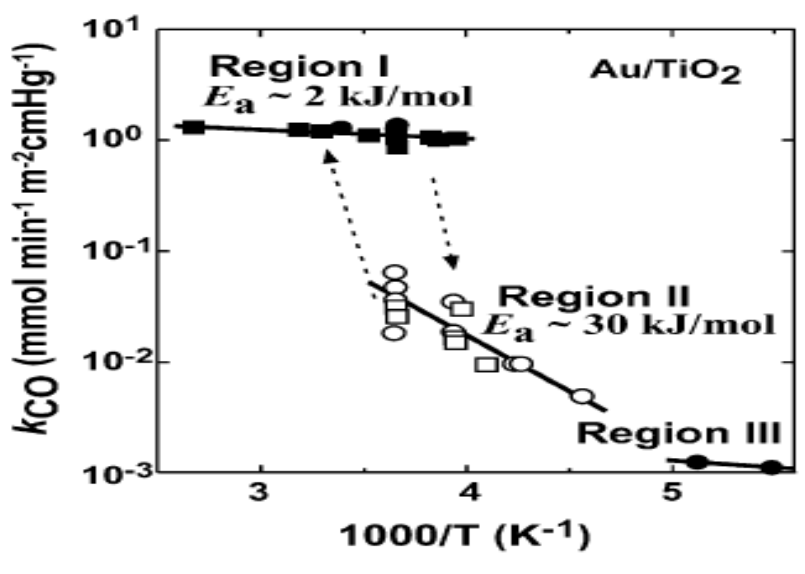

Figure 7: Arrhenius plots for $\mathrm{CO}$ oxidation over $\mathrm{Au} / \mathrm{TiO} 2$ catalyst[84]
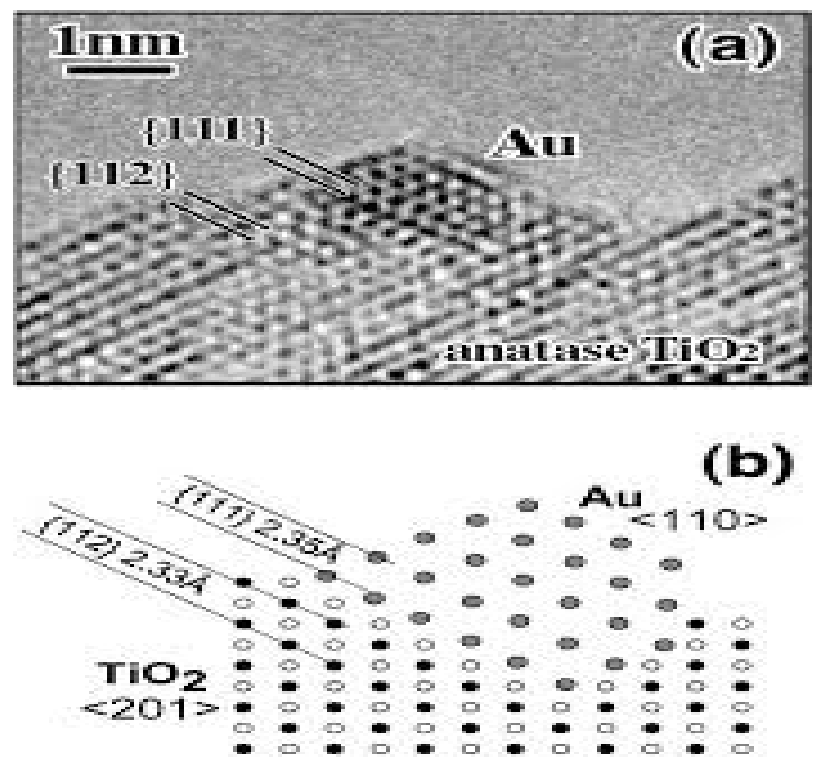

Figure 8: (a) Transmission electron micrograph for $\mathrm{Au} / \mathrm{TiO} 2$ contact interface and (b) its schematic diagram [84]

energy of activation of nearly zero [87]. In addition to above report, a few other interesting features of $\mathrm{Au} / \mathrm{TiO} 2$ catalysts were described by using model catalysts [78] and by high resolution transmission electron microscopy [78, 89, and 90]. Fig. 8 shows typical epitaxial structure of $\mathrm{Au}$ with it support contact [89]. The empty space connecting particles of $\mathrm{TiO}_{2}$ pictured additional particles of $\mathrm{Au}$ in the process of conversion of the metal to its oxides at reasonable temperatures.

Adsorption of $\mathrm{CO}$ on $\mathrm{Au}$ surfaces is one of the important steps in oxidation of CO. Boccuzzi et al. have found that $\mathrm{Au} / \mathrm{TiO} 2$ catalyst prepared by depositionprecipitation method contains three different Au sites for $\mathrm{CO}$ adsorption depending on conditions of pretreatment [83]. Adsorption of $\mathrm{CO}$ at successive sites of Au metal
(2110-2120 $\mathrm{cm}^{-1}$ ) subsequent to heating of the Au metal in the presence of air at increased temperature, adsorption of $\mathrm{CO}$ on $\mathrm{Au}$ oxide $\left(2176 \mathrm{~cm}^{-1}\right)$ showing much oxidation and hydration, and successive /crossed-bonded adsorption of $\mathrm{CO}$ in contact with tiny clusters of Au (2050-1900 $\left.\mathrm{cm}^{-1}\right)$ brought about through disturbances caused through the formation of negative charge on support reduction by $\mathrm{H}_{2}$. The study of the adsorption of $\mathrm{CO}$ and oxygen over $\mathrm{Au} /$ $\mathrm{TiO}_{2}$ employing fixed bed flow reactor equipped with mass spectroscopy has shown that $\mathrm{CO}$ and $\mathrm{O}_{2}$ adsorption takes place promptly, and the production of $\mathrm{CO}_{2}$ rises pending on when saturation is achieved through adsorption of oxygen on perimeter sites being reduced [91]. Moreover, moisture also enhances oxidation of $\mathrm{CO}$ over $\mathrm{Au} / \mathrm{TiO}_{2}$. Catalytic activity is so low under dry condition (0.1 ppm $\mathrm{H}_{2} \mathrm{O}$ ) than under the ordinary experimental condition (about 3 ppm $\mathrm{H}_{2} \mathrm{O}$ ) [92].

\subsubsection{Oxidation by $\mathrm{Au} / \mathrm{CeO}_{2}$}

Oxidation of $\mathrm{CO}$ catalyzed by $\mathrm{Au}$ atoms supported by dissimilar oxides was addressed through several theoretical studies [93], oxidation has been modeled in the presence of oxygen ad species yielding to formation of surface CO-O intermediate complexes that leads to oxidation of $\mathrm{CO}$ with $\mathrm{CO}_{2}$ desorption. Au-based catalysts Activity towards oxidation of $\mathrm{CO}$ is known to be sensitive to (i) method of preparation; (ii) nature of supports; (iii) size of Au particles; (iv)pre-treatment conditions; and (v) $\mathrm{Au}$-support interactions [94]. Among all, support choice is of primary importance. The support usually plays multiple roles, such as mechanical functionality, i.e., to disperse and stabilize supported nanoparticles against agglomeration and at same time it could participate in catalytic process. Conventionally, CO oxidation supports can be classified depending on their reducibility or ability to supply reactive oxygen: reducible materials such as $\mathrm{CeO}_{2}, \mathrm{Fe}_{2} \mathrm{O}_{3}, \mathrm{CoO}_{x}$, with non-reducible supports like $\mathrm{MgO}$ and $\mathrm{Al}_{2} \mathrm{O}_{3}$. Currently, Au support on reducible transition metal oxide always exhibits better activity for the oxidation of $\mathrm{CO}$ under Au support on non-reducible oxides [95]. Nevertheless, non-reducible materials having electron-rich oxygen vacancies may enhance activity of Au catalyst by activating gaseous oxygen [96]. As a result of chemical properties of ceria, it has become one of the most promising supports for oxidation reactions as it is being studied widely [97]. Relevance of $\mathrm{CeO}_{2}$, as support for nanoparticles of $\mathrm{Au}$, is mainly based on its high capacity to store oxygen which results from oxygen mobility present in its lattice [98]. The latter is 


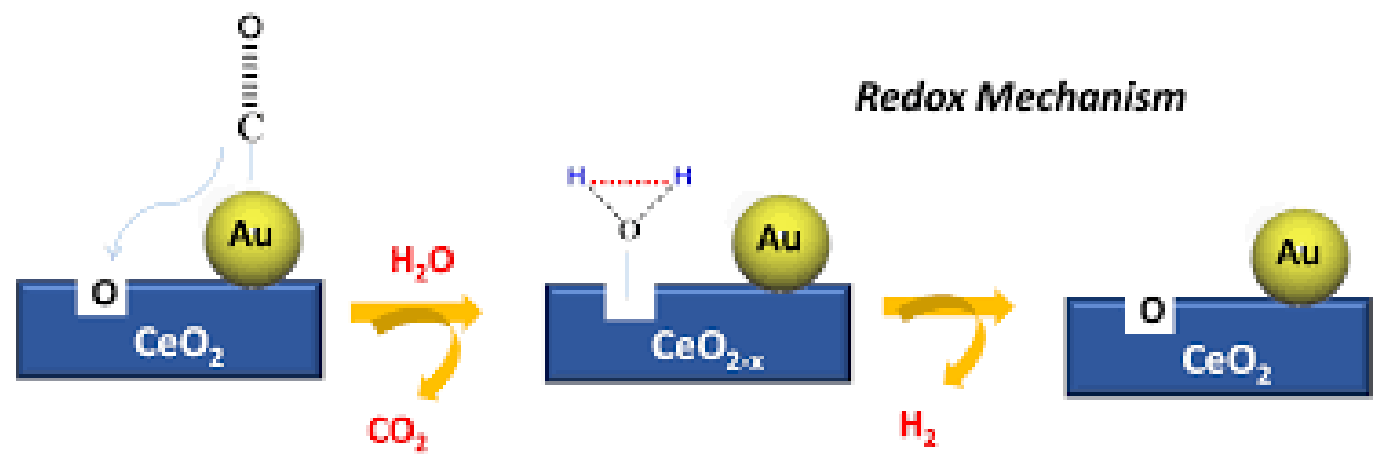

Figure 9: Simplified $\mathrm{CO}$ oxidation mechanism in a model $\mathrm{Au} / \mathrm{CeO} 2$ system. Oxygen vacancies of ceria on the $\mathrm{Au} / \mathrm{CeO} 2$ contact perimeter can chemisorb gaseous oxygen $(\mathrm{O}==\mathrm{O} \rightarrow \mathrm{V}$ ) $)$ producing activated oxygen atoms able to react with $\mathrm{CO}$ molecules adsorbed on Au particles $(\mathrm{C}==0 \rightarrow A u)$ to generate gaseous $\mathrm{CO} 2$ and new oxygen vacancies[93]

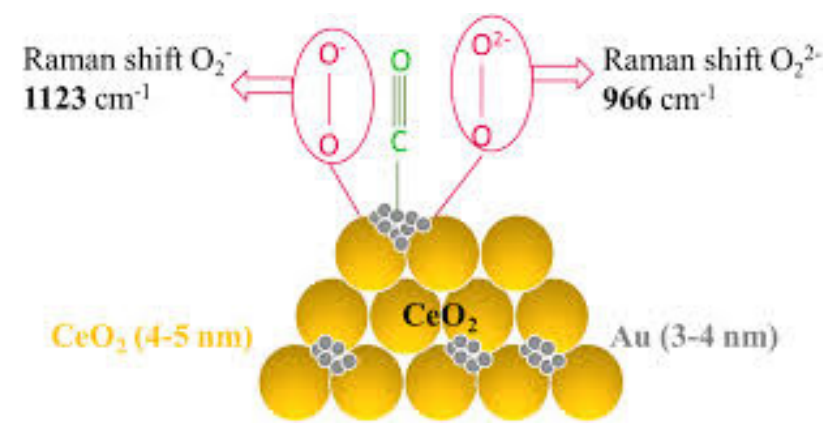

Figure 10: Schematic representation of $\mathrm{CO}$ oxidation catalyzed by gold on nanocrystalline reflecting the role of oxygen reactive species. (CeO2 yellow, Au gre)y. The position of the characteristic Raman bands of superoxide $(02-, 1123 \mathrm{~cm}-1)$ and peroxide (022-, $966 \mathrm{~cm}-1)$ species are shown). Adapted from Guzman et al [103].

directly correlated to creation, stabilization, with oxygen vacancies diffusion, especially on oxide surfaces, as a result of reversible redox behavior of $\mathrm{Ce} 4+/ \mathrm{Ce} 3+$ couple hence, resulting in the formation of non-stoichiometric oxides $\mathrm{CeO} 2-\mathrm{x}(0<\mathrm{x}<0.5)$. The concentration of these structural defects is usually correlated with catalytic activity in reactions involving CO elimination [99]. In addition, these defects may act also as an activation point of $\mathrm{CO}$ and $\mathrm{O}_{2}$ molecules, facilitating reaction. Indeed, ceria participation in reaction mechanism is vital since the main criticism towards CO oxidation mechanisms involving only $\mathrm{Au}$ atoms is related to poor capacity of $\mathrm{Au}$ for oxygen chemisorption and activation [100]. Figure 9 shows a simplified reaction mechanism of $\mathrm{CO}$ oxidation over $\mathrm{Au} / \mathrm{CeO}_{2}$. Rapid $\mathrm{Ce}^{4+} \mathrm{Ce}^{3+}$ inter-conversion leads to generation of oxygen vacancies (equation 1) where $\mathrm{O}_{2}$ can be chemisorbed (Equation 2). In parallel, CO sits on metallic Au particles (Equation 3), leading to adsorbed $\mathrm{CO}$ that would further react on metal/oxide interface with $\mathrm{O}_{2}$ activated on support vacancy producing final $\mathrm{CO}_{2}$.
Oxygen species bonded to $\mathrm{CeO}_{2}$ are incapacitated by $\mathrm{Au}$ clusters consequently promoting production of plenty reactive species according few authors [101]. In some cases, these reactive sites can participate in the reaction mechanism by creating activated species directly from the reactants mixture (e.g., peroxi-like and superoxilike species), potentiating the oxidation reactions [102]. Guzman et al. clearly demonstrate the role of these oxygen activated species in the $\mathrm{CO}$ oxidation process using in situ Raman spectroscopy. They obtained Raman spectra of $\mathrm{Au}$ support on Nano crystalline ceria before and during the CO oxidation test, detecting bands at 1123 and $966 \mathrm{~cm}^{-1}$ ascribed to superoxide and peroxide species, respectively [103]. These bands virtually disappear during CO oxidation, indicating the direct participation of these oxygen species in the reaction. The study also stated that the formation of defect sites on Nano crystalline ceria is promoted by the $\mathrm{Au}$ presence underlying the importance of the $\mathrm{Au} / \mathrm{CeO}_{2}$ contact and their synergistic effect. Figure 10 schematizes the $\mathrm{CO}$ oxidation process picturing the direct participation of reactive oxygen species in the process.

Given the importance of oxygen defects in Ce in order to achieve better performances in CO oxidation, there has been a research trend in last decade aiming to potentiate formation of oxygen vacancy on Ce lattice. $\mathrm{O}^{2-}$ removal from surface or lattice of oxide may be achieved via several methods such as thermal treatments, electron irradiation, X-rays exposition, or chemical reduction [99, 104, 105]. Nevertheless, in the case of catalytic applications, most popular strategy is to dope ceria with lower valence metallic cations [106]. Oxygen vacancies formation of $\mathrm{CeO}_{2}-\mathrm{MOx}$ support is directly related to formation of a Ce-M solid solution. Dopant ion can modify both the chemical properties and the structural features of ceria because of the similarities of it ionic radius and electronegativity with that of ceria and is thus regarded 
as the most suitable ceria modifiers. These dopants can provoke structural distortions such as ceria lattice contraction, thus favoring formation of oxygen vacancies through mechanical stress.

In summary, $\mathrm{Au} / \mathrm{CeO}_{2}$-based catalysts represent an excellent option for the direct oxidation of $\mathrm{CO}$ in contaminated atmospheres with potential utilization in environmental catalysis. A number of factors can influence catalytic properties of this type of material, such as Au particle size, method of preparation, and $\mathrm{Au} /$ $\mathrm{CeO}_{2}$ contact. However, there is general agreement on the important role played by Ce. With all other factors optimized (Nano Au particle size, metallic dispersion, etc.), highly effective $\mathrm{CO}$ oxidation catalysts can be produced only when ceria electronic properties and defect concentration is tailored with an adequate dopant. Vast efforts have been made in recent years aiming to achieve an optimum performance, but there is still some room for further improvements. Limited number of reports on $\mathrm{CO}$ oxidation by $\mathrm{Au} / \mathrm{CeO}_{2}$ is available; some are report from Matteo $\mathrm{F}$ et.al. They also report that, low-temperature oxidation of molecular CO can be efficiently catalyzed by highly dispersed $\mathrm{Au}$ nanoparticles support on transitionmetal oxides. Also, according to this report, catalysts activity is controlled by many factors, most notably is, the size of metal cluster, ability of support to supply $\mathrm{O}_{2}$ during reaction with excess electrons at interface of metal/oxide determining oxidation state of the Au atoms. Ceria can store oxygen therefore because of this fact it is the most efficient reducible oxides among others, as the activities of these oxides is generally elevated catalytically.

\subsubsection{Preparation of $\mathrm{Au} / \mathrm{CeO}_{2}$ Catalysts}

So many methods have been used to prepare $\mathrm{Au} / \mathrm{CeO}_{2}$ catalyst some of these methods include depositionprecipitation (DP) method that is commonly employed; Jia $\mathrm{M} L$ et al report the preparation of $\mathrm{Au} / \mathrm{CeO} 2$ via this method. According to this report, the support was made through preparation of an aqueous precipitate and by using ammonia with adequate amount of PEG-6000 in the various steps of the process, accompanied by treatment in micro-wave. On the other hand, the catalyst $\mathrm{Au}$ ) is prepared through dissolution of a suitable amount of chloroauric acid ( $\mathrm{HAuCl} 4 \cdot 3 \mathrm{H} 2 \mathrm{O})$ in deionized water, followed by $\mathrm{pH}$ adjustment, addition of the support and heating. According to this report, the catalyst showed a high catalytic activity [107]. Another method is an interesting advancement like employing supercritical $\mathrm{CO}_{2}$ in the same manner with anti-solvent engaged in $\mathrm{Au}$ catalyst production mostly when this catalyst is supported on ceria [108]. The catalyst precipitates on adding the precursor solution to supercritical $\mathrm{CO}_{2}$. Rise in activity of Au catalyst is observed when it is related with systems that are produced ordinarily or by traditional process; such conduct can be expressed as arising from change in velocity of nucleation when making the catalyst. Newly, a novel method based on the photo-thermal effect generated from localized surface $\mathrm{Au}$ Plasmon resonance (LSPR) has been proposed for preparing $\mathrm{Au} / \mathrm{CeO} 2$ core-shell structures [109]. Core shell structures of Au catalyst supported on ceria was achieved by way of combining ceria solution with reverse micelle $\mathrm{Au}$ (III) solution and solution of sodium hydroxide $(\mathrm{NaOH})$ according to the findings of Mitsudome et al. [110]. Combination of the above solutions takes place giving rise to oxidation-reduction reaction of $\mathrm{Au}$ (zero oxidation state) along with ceria (oxidation state of IV) leading to core shell structure of $\mathrm{Au}$ support on $\mathrm{CeO}_{2}$. Furthermore, utmost selectivity of alkene is acquired from the combined outcome of the above structure in partial hydrogenation reaction of diverse alkynes. Bera and Hedge [111] proposed the solution combustion method to prepare $\mathrm{Au} / \mathrm{CeO} 2$ catalysts. In this method, $\mathrm{Au}$ remains in ionic form until a thermal treatment at 800 a $\mathrm{C}$ is applied. Synthesis of $\mathrm{Au}$ catalyst on $\mathrm{CeO}_{2}$ support in vapor phase was recommended by Yang et al. [112]. The above process involves annihilating the targeted metal through means of employing $2^{\text {nd }}$ harmonic generation neodymium-doped yttrium aluminum garnet (Nd-YAG) laser on top of the cold plate where the oxide support is placed. This preparation method appears to be very versatile, i.e., a variety of efficient catalysts can be designed by using simple and flexible control of different synthetic parameters. Another flexible means of processing $\mathrm{Au}$ catalyst is to decompose a precursor from single-source [113]. According to R Reina et al, the method normally uses the double complex salts (DCS) of transition metals, ionic compounds for which cation and anion are coordination compounds, and appears so convenient in synthesizing catalysts consisting of two metals known as bimetallic. This catalyst is processed by two ways: impregnation of salts consisting of only single metal known as monometallic salt progressively on the support, other way also involve impregnation of DCS organic solution. Spreading the catalyst on supports with high surface area is another easy and frequent way of forming the catalyst as employed in previous years. Rise in dispersion of $\mathrm{Au}$ on the surface of support and also ratio of rise in surface to the bulk will likely occur when this approach is employed and for that reason complete $\mathrm{Au} / \mathrm{CeO} 2$ interface exposure to the reactants. The latter 
effect is observed when the size of both $\mathrm{Au}$ and $\mathrm{CeO}_{2}$ nanoparticles is similar. $R$ Reina et al. [114] performed an extensive study over the deposition of bare or transition metal-doped $\mathrm{Au} / \mathrm{CeO}_{2}$ catalyst over alumina.

\subsubsection{Oxidation Reactions Catalyzed by $\mathrm{Au} / \mathrm{CeO}_{2}$}

A well-known property of large volume of metallic $\mathrm{Au}$ is its high inertness and non-changing character being ideal for jewelry purposes. Of all the transition metals, Au possess small chemical properties and consequently termed "least" in reaction chiefly because of it small catalytic activity [115]. On the contrary, this becomes untrue as small particles of Au at Nano level spread over a support possesses high reactivity primarily when a metallic oxide or activated carbon is used as support [116]. Among different options, ceria results frequently in an optimum choice as support for Au nanoparticles. As a result of its excellent redox features, Ce is probably the most extended support employed in oxidation catalysis, and $\mathrm{Au} / \mathrm{CeO}_{2}$ combinations result in a perfect synergy. Here, attention is driven to some number of reactions in that $\mathrm{Au} / \mathrm{CeO}_{2}$-based catalysts have an outstanding behavior. Several reports were made on the oxidation reaction catalyst by $\mathrm{Au} / \mathrm{CeO} 2$, some of which were reported at room temperature, in which case the induction period arising from unreduced cationic $\mathrm{Au}$ was disclosed and the effect of humidity in the reaction was investigated during induction and deactivation period. After the induction period, the deactivation phenomena of $\mathrm{Au} / \mathrm{CeO}_{2}$ catalyst at varied rates under both wet and dry streams were observed. In contrast, in slow and fast deactivation was made which shows a slow deactivation under dry stream, a fast deactivation in wet stream was first observed due to rapid blockage of active sites by water adsorption, followed by a slow deactivation rate due to gradual formation of surface carbonate species over catalyst with time on stream. And a mechanism was proposed to illustrate the existence of induction period under both wet and dry streams [117]. Recently, a report on the effect of $\mathrm{Au} / \mathrm{CeO} 2$ interface was given for the catalytic oxidation of $\mathrm{CO}$ over Au nanoparticles support on ceria Nanocrystals by Ha Hyunwoo et al were they synthesized $\mathrm{Au}$ nanoparticles (NPs) and modeled it through simulations using DFT calculations, thereby, providing an insights into the catalytic function of CeO2-supported $\mathrm{Au}$ NPs toward CO oxidation depending on the shape of $\mathrm{CeO} 2$ and ratio of $\mathrm{CO} / 02$. [118]. Fernasi $\mathrm{M}$ et al also gave a report on the mechanism of $\mathrm{CO}$ oxidation on $\mathrm{Au} / \mathrm{CeO} 2$ catalysts: Activity of Substitutional $\mathrm{Au} 3+/ \mathrm{Au}+$ Cations and Deactivation of Supported $\mathrm{Au}+$ Adatoms via theoretical findings. Through their calculations, they predict that the reactivity of $\mathrm{Au}$ NPs nucleated at oxygen vacancies can be recovered for cluster sizes as small as Au2 [119]

\subsubsection{Oxidation by $\mathrm{Au} / \mathrm{SiO}_{2}$}

A lot of advances have been made in the area of $\mathrm{Au}$ catalysis; some of these reports are on $\mathrm{CO}$ oxidation by $\mathrm{Au} /$ $\mathrm{SiO}_{2}$ expressed by $\mathrm{H}$. Zhu. et.al according to this report, it was recorded previously that $\mathrm{SiO}_{2}$ has been shown to be an unsuitable support for preparing Au catalysts for CO oxidation [120,121]. Although Au support on mesoporous oxide of silicon display particles of Au that are not large if processed through co-assembly approach, yet the inactiveness inherent by this catalyst towards the oxidation of CO cannot be over emphasized. This is based on the studies of the above author [121, 122, and 123]. The reason why the supported Au catalyst is inactive is because of the fragileness of the interface at both $\mathrm{Au}$ and the support, and also lack of proper elimination of small pieces of this catalyst as learned from advanced research [121, 122, and 123]. We have presently observed from advance studies that this catalyst displays elevated activity towards oxidation of $\mathrm{CO}$ when it is formed from a precursor [124-126, 127]. The present challenge still notwithstanding cross-examines the possibility of synthesizing this catalyst support on $\mathrm{SiO}_{2}$ in the absence of such nanopores. The effectiveness of the cross-examination proves that the above challenge can be overcome because the pore channels of the catalyst is expected to stop the particles of Au situated in the pores from developing [127, 128, 129]. More research were carried out and more emphasis made as well in employing precursor of Au support on ethylene chloride [130-133], also expressing the possibility of forming mesoporous $\mathrm{SiO}_{2}$ with no obligation of forming active $\mathrm{Au}$ catalyst support on same oxide of silicon. Au support on mesoporous silicon oxide is given much scrutiny [121, 134, and 135], there is no literature work on the activity of $\mathrm{Au}$ catalyst and no esteemed facts concerning what will become of the particles of $\mathrm{Au}$ when heated at elevation temperature in converting it to oxide. These present some of the deficiencies in earlier research. Hence, further work provided a solid example that $\mathrm{Au} /$ fumed $\mathrm{SiO}_{2}$ could be very active for $\mathrm{CO}$ oxidation.

\subsubsection{Effect of catalyst pretreatment}

Pretreatment is crucial in activation of $\mathrm{Au} / \mathrm{SiO}_{2}$, it importance lies in the removal of organic ligands and fragments. A careful inspection of literature indicated analogous scenarios. For instance, $\mathrm{Au} / \mathrm{TiO}_{2}$ catalysts have 
been prepared using $\mathrm{Au}\left(\mathrm{PPh}_{3}\right) 3\left(\mathrm{NO}_{3}\right)$ [134], $\left[\mathrm{Au}_{9}\left(\mathrm{PPh}_{3}\right)_{8}\right]$ $\left(\mathrm{NO}_{3}\right)_{3}$ [135], $(\mathrm{Au}) \mathrm{x}\left(\mathrm{C}_{6} \mathrm{H}_{5} \mathrm{CH}_{3}\right)_{2}$ [136], $\left[\mathrm{Au}_{6}\left(\mathrm{PPh}_{3}\right)_{6}\right]\left(\mathrm{BF}_{4}\right)_{2}$ [137], $\left.\mathrm{Au}_{4}[\text { (ptolyl)NCN(p-tolyl) }]_{4}[138], \mathrm{Au}_{13}\left[\mathrm{PPh}_{3}\right] 4\left[\mathrm{~S}_{(\mathrm{CH}}\right) 11 \mathrm{CH}_{3}\right]_{4}$ [139], or polymer-stabilized Au particles [140] as precursor, and others have made $\mathrm{Au} / \mathrm{SiO}_{2}$ using $\mathrm{Au}\left(\mathrm{PPh}_{3}\right) 3 \mathrm{Cl}$ [141] along with ligand capped nanoparticles of $\mathrm{Au}$ [142]. Aminosilane was charged with $\mathrm{Au}$, this was expressed by Mou et al. [143]. Activity of a Catalyst is favored or will be rised when fragments/protecting ligand are eliminated during the reaction process according to the above references, but achieving this is quite challenging [144]. The same setback is also experience when using ligand-protected colloid [145]. According to the principles of chemistry of surfaces, metals having spotless surfaces have good reactivity but the activeness of such surfaces decrease when the surface is contaminated. [146]. Thus, catalyst pretreatment is very important for such types of supported $\mathrm{Au}$ catalysts, and pretreatment conditions should be rigorous enough to yield bare Au particles, but not so harsh that it result to very large Au particles.

\subsubsection{Implication of post-treatment in both acid/basic medium}

Activity of Au catalyst support on $\mathrm{SiO}_{2}$ is not the same especially when handled in distinct medium (Fig. 7). Treating calcined (and activated) $\mathrm{Au} / \mathrm{SiO}_{2}$ in $\mathrm{NaOH}$ solution, followed by re-calcination promote the activity, whereas the treatment using $\mathrm{HNO}_{3}$ vapor had a harmful effect on activity. Some researchers used ammonia $\left(\mathrm{NH}_{3}\right)$ or $\mathrm{NaOH}$ solutions to treat the chloride-rich $\mathrm{Au} / \mathrm{Al}_{2} \mathrm{O}_{3}$ or $\mathrm{Au} / \mathrm{TiO}_{2}$ and found that the method could remove excessive chloride [147,148]. No ppm-level chloride is obtained if the contemporary means of synthesizing $\mathrm{Au}$ catalyst support on silicon is adapted, this should be taken into consideration [127], Only further heating of $\mathrm{Au}$ catalyst on $\mathrm{SiO}_{2}$ support in $\mathrm{NaOH}$ solution shows a good effect. Thus, it is speculated that the role of pretreatment in our case is to tune the surface property of the support or change the structure of the active sites. No much literature work explaining the effectiveness of the oxidation of $\mathrm{CO}_{2}$ or even the characteristic that acid and base shares in common. As it was taken into account that Au catalyst formed in solution of base shows a rise in the activity, on the contrary, when processed in solution of acid, less activity is obtained [149,150]. Au on certain incipient metal hydroxides was more active than $\mathrm{Au}$ on corresponding metal oxides according to Iwasawa et al. [151]. Liquid-phase CO oxidation on Au nanotubes was significantly promoted in the presence of a basic solution than water according to Dumesic et al. [152].
Basic medium favors Pt catalyst support on the oxide of aluminum by infrared (IR) spectroscopy in the oxidation of CO; this is based on Lefferts et al. [153]. Potential capacity of acid-base characteristic in the oxidation of CO cannot be overemphasis as a matter of fact. On the other hand, reactivity of Au catalyst is influenced by it particles shape as expressed by both Haruta/Goodman [15]. Perhaps, when Au catalyst was heated and treated, it particle structure undergoes transformation.

\subsection{Propylene Epoxidation}

Due to the growing environmental issues in chemical synthesis and processing, there has been increasing interest in the development of new processes for minimizing pollution and reducing energy consumption. Heterogeneous catalysis plays a crucial role in this respect, since it is widely used to reduce emissions from automobiles, reduce byproducts, and improve the selectivity of important chemical products in the petrochemical as well as other chemical industries [154]. Computational and experimental investigators have been working together to better understand fundamental characteristics of a wide range of catalytic reactions. Haruta's group initially started working with $\mathrm{Au}$ nanoparticles supported on $\mathrm{TiO}_{2}$, but they gradually transitioned to mesoporous titanosilicates $\left(\mathrm{Ti}^{-} \mathrm{SiO}_{2}\right)$ as the supports [155]. Delgass's group has focused on microporous titanosilicate supports, which demonstrate better results, even with low Au loadings [156]. Jingjing et al focus on the selective epoxidation of propylene to yield propylene oxide ( $\mathrm{PO}$ ) using heterogeneous Au-based catalysts. According to their report, they ascribed The catalytic activity of $\mathrm{Au}$ and Au alloy nanoparticles (a few $\mathrm{nm}$ in size) to various mechanisms, involving reactions occurring at neutral $\mathrm{Au}$ atoms that differ from bulk $\mathrm{Au}$ atoms (due to different degrees of coordination), quantum size effects that change the electronic structures of nanoparticles, or charge modification of Au atoms through the interaction with oxide supports [157]. This report gives a hint on propylene epoxidation of $\mathrm{Au}$ with various oxide support such as; $\mathrm{Au} / \mathrm{TiO} 2, \mathrm{Au} / \mathrm{CeO} 2$ and $\mathrm{Au} / \mathrm{SiO} 2$

\subsubsection{Propylene Epoxidation $\mathrm{Au} / \mathrm{TiO}_{2}$}

Operation of Au catalyst support on Ti in the presence of oxygen to reduce gas in propylene epoxidation to it oxide have been carried out through experiments and density functional theory calculations (DFT). It was observed that 
using both $\mathrm{H}_{2}$ and $\mathrm{CO}$ as co-reactants, $\mathrm{PO}$ can be produced. The output of PO was far lower with CO compared to $\mathrm{H}_{2}$. Operation of $\mathrm{CO}$ as co-reactant is an evidence that support oxygen were employed during processing of propylene oxide as expressed through analysis of steady-state isotopic transient kinetics [158]. Present study explores the role of co-reactants in the direct epoxidation of propene to $\mathrm{PO}$ on $\mathrm{Au} / \mathrm{TiO} 2$ catalysts, using experimental and theoretical tools. When The $\mathrm{H}_{2}$ was substituted by $\mathrm{CO}$ as a co-reactant, $\mathrm{PO}$ formation was observed but with lower PO yields. PO selectivity, on the other hand, was $>99 \%$ in both cases and catalyst deactivation, which is a common feature on $\mathrm{Au} / \mathrm{TiO}_{2}$, was also observed in the case of CO, with time on stream [158].

\subsubsection{Reaction path way of Propylene Epoxidation $\mathrm{Au} / \mathrm{TiO}_{2}$} Sobolev Vladimir et al report on the mechanism of reaction of Au NPs supported on $\mathrm{TiO} 2$ which was known to catalyze vapor-phase epoxidation of propylene with molecular oxygen in the presence of $\mathrm{H} 2$ as the necessary reducing co reagent. Were they report the use of carbon monoxide instead of hydrogen to accomplish such reaction. The reaction mechanism which they proposed involves the formation of specific oxygen species arising from $\mathrm{O} 2$ on catalytic sites reduced with CO. which is relative to the generation of highly reactive oxygen species (detectable by oxygen isotopic exchange) on the surface of $\mathrm{Au} / \mathrm{TiO} 2$ treated preliminarily with CO [159]. Recently in 2018, Ji J et al also report the reaction mechanism of direct propylene epoxidation over $\mathrm{Au} / \mathrm{TiO} 2 / \mathrm{SiO} 2$ via theoritical simulations where they produced the experimental data such as the product distributions as a function of temperature, pressure, feed composition etc. they also report on the influence of structure on the catalyst performance and the influence of close interactions the kinetics of the reaction at maximum coverage. Using this model, they identify an operating condition which helps them to control the efficiency of hydrogen of the system. Such conditions are; low reaction temperature, low hydrogen feed concentration, and a relatively high oxygen feed concentration. Their work creates a route for exploring more complex bimetallic catalysts for simultaneously achieving high selectivity and activity for the synthesis of propylene oxidation. [160]

\subsubsection{Propylene Epoxidation $\mathrm{Au} / \mathrm{CeO}_{2}$}

This reports a one-pot epoxidation of alkenes with $\mathrm{O}_{2}$, performed with nanoparticles of $\mathrm{Au} / \mathrm{CeO}_{2}$ and a silylated materials of Ti-MCM-41 with two promoters; dye and hydrocarbon, the initiator is capable of forming organo $\mathrm{Au}$ species which promote hydrocarbon formation (3-methylpentane, ethylbenzene, or cumene) a rise in the yield of alkene is achieved when hydro peroxides is employed in epoxidation involving Ti. The epoxidation reaction of 1-octene with molecular oxygen $\mathrm{PPO}_{2} \quad 1 / 412$ barsP at $90^{\circ} \mathrm{C}$ over azobisisobutyronitrile (AIBN) $-\mathrm{Au} / \mathrm{CeO}_{2}$ + Ti-MCM-41-silylated catalytic system results in alkene conversions close to $9 \%$ with epoxide decomposition around $90 \%$ when working with cumene as an atoning hydrocarbon [161]. The synthesis of meso-structured $\mathrm{CeO}_{2}$ was performed. Deposition of the $\mathrm{Au}$ particles on $\mathrm{CeO}_{2}$ support was carried out by a deposition-precipitation method with $\mathrm{HAuCl}_{4} \cdot 3 \mathrm{H}_{2} \mathrm{O}$ as the source of $\mathrm{Au}$, following the experimental procedure detailed in [162]. Thus, a solution of $0.2 \mathrm{M}$ of $\mathrm{NaOH}$ was added (drop by drop) to $0.6 \mathrm{~g}$ of $\mathrm{HAuCl}_{4} \cdot 3 \mathrm{H}_{2} \mathrm{O}$ mixed with distilled water up to $70 \mathrm{ml}$ in volume so that the $\mathrm{pH}$ of the solution will be regulated to about 10, then poured into $5.7 \mathrm{~g} \mathrm{CeO}_{2}$ salt dissolved in distilled water, while stirring so fast. The mixture obtained was continuously stirred at room temperature for 15 to 16 h. Once the solid had been recovered by filtration, it was washed thoroughly with water and oven dried at $100^{\circ} \mathrm{C}$ for approximately $12 \mathrm{~h}$. Both the solid chemical analysis with X-ray fluorescence (XRF) has it that the Au catalyst on ceria support processed, have a gram $\%$ of almost 2.5 . Mesoporous $\mathrm{TiO}_{2}$ was prepared in gram percentage of about $2.1[163,164]$, first of all by mixing 3.11g cetyltrimethyl ammonium bromide in 20.88 distilled water measured in grams. This is accompanied by addition of $5.39 \mathrm{~g}$ of tetramethyl ammonium hydroxide together with $0.21 \mathrm{~g}$ of $\mathrm{Ti}$ tetraethoxide to the solution mixture followed by agitation of the solution to ensure complete dissolution of Ti. A gel was obtained on inclusion of $3.43 \mathrm{~g}$ silica which undergoes agitation in an hour under controlled room temperature. The whole medium is then autoclaved, heated at $100^{\circ} \mathrm{C}$ for two days under internal pressure. After which the solution is filtered and solid materials were acquired which is washed and dried for a day under a specific temperature of about $60^{\circ} \mathrm{C}$. The solid material obtained is air dried under nitrogen flow at $540^{\circ} \mathrm{C}$ and then further dried under dry air flow also at $540^{\circ} \mathrm{C}$ in a tubular reactor made of quartz; this is accompanied by room temperature cooling. Ultimately, about 2.1 weight percentage (wt\%) catalyst was achieved (expressed as $\mathrm{TiO}_{2}$ ) based on chemical analysis. This solid has a specific surface of $1090 \mathrm{~m}^{2} \cdot \mathrm{g}^{-1}$ with an average pore size distribution of 35 to $38 \AA$, and has a band in the ultra violet-visible (UV-Vis) spectrum centered at 220 $\mathrm{nm}$. Another catalyst (Ti-MCM-41) was made by first of all drying Ti-MCM-41 at 2.0g in 2 hours under a condition of 
temperature $\left(100^{\circ} \mathrm{C}\right)$ and pressure $\left(10^{-3}\right)$ and then allowing it to cool under controlled temperature (room tempt) and then $1.88 \mathrm{~g}$ hexamethyldisilizane solution mixed with $30 \mathrm{~g}$ of toluene is put on, whole mixture of the solution is then refluxed for 1 hour $30 \mathrm{~min}$ at temperature of $120^{\circ} \mathrm{C}$ and washed with toluene. This is followed by drying of the catalyst obtained under temperature condition of $60^{\circ} \mathrm{C}$. The catalyst is obtained in solid form and weighted two wt $\%$ (expressed as $\mathrm{TiO}_{2}$ ) based on chemical analysis. This solid has a specific surface of $965 \mathrm{~m}^{2} . \mathrm{g}^{1}$, and has a band in the UV-Vis spectrum centered at $220 \mathrm{~nm}$. For comparison purposes samples of the Au/MCM-41 and $\mathrm{Au} / \mathrm{Ti}$-MCM-41 have also been prepared. The preparation of a purely siliceous MCM-41 mesoporous material ( $\mathrm{Si} /$ Al molar ratio $=1$ ) was carried out as follows. Typically, $5.0 \mathrm{~g}$ of $\mathrm{C}_{16} \mathrm{TABr}$ was diluted in $33.5 \mathrm{~g}$ of water under temperature condition of $40^{\circ} \mathrm{C}$. Solution of $8.65 \mathrm{~g} \mathrm{TMAOH}$ measured in percentage weight of about 25 was spread side by side an aerosol weighing almost $1 \mathrm{~g}$. And under room temperature condition, mixing together of the final suspension and the early solution of $\mathrm{C}_{16} \mathrm{TABr}$ obtained was done. Consequently, $4.52 \mathrm{~g}$ of the aerosol contained in the resultant solution was hydrolyzed under stirring (350 $\mathrm{rpm}$ ) at room temperature. The formed gel was maintained under stirring for $1 \mathrm{~h}$ until complete homogenization. Then, the gel ( $\mathrm{pH}$ 13.8) was disposed into an internally Teflon-covered autoclave and heated under autogeneous pressure at $135^{\circ} \mathrm{C}$ for $24 \mathrm{~h}$. The obtained solid was filtered off, washed with abundant water, and oven dried at $60^{\circ} \mathrm{C}$ for $12 \mathrm{~h}$. At last, heating at very high temperature was done in a tubular reactor in order to get rid of the organic substances in the solid, but with further increase in temperature from room temperature to $540{ }^{\circ} \mathrm{C}$ (under dry $\mathrm{N} 2$ flow) followed by a step at $540{ }^{\circ} \mathrm{C}$ for $6 \mathrm{~h}$ (under dry air flow). The Si-MCM-41 sample obtained presents a specific surface area of $1000 \mathrm{~m}^{2} \cdot \mathrm{g}^{-1}$, with an average pore size distribution of 35 to $38 \AA$ A. DP approach was applied in the displacement of the particles of $\mathrm{Au}$ on both of the mesoporous materials (silicon/titanium MCM-41) surface. $1.2 \mathrm{~g} \mathrm{HAuCl}_{4} 3 \mathrm{H}_{2} \mathrm{O}$ was consistently diluted in 100 $\mathrm{ml}$ of water (Milli-Q Quality) and the $\mathrm{pH}$ of the obtained solution was modified with drop to drop addition of 0.2 $\mathrm{M}$ of $\mathrm{NaOH}$ solution until $\mathrm{pH} 7$ to 8 was reached. Then, the mentioned Au-containing solution was added to a suspension of MCM-41 material type measured in $6.0 \mathrm{~g}$ in a moderate volume of water about $200 \mathrm{ml}$, followed by strong agitation under controlled room temperature condition. The mixture was maintained under stirring at room temperature for 15 to $16 \mathrm{~h}$. It took one day of drying under temperature condition of about $100^{\circ} \mathrm{C}$ to achieve the final solid through filtration and prolonged distilled washing. The Au loading on the MCM-41-type supports was 4.5 and $2.3 \mathrm{wt} \%$ for Au/MCM-41 and Au/Ti-MCM41 catalytic samples, respectively, based on XRF measurements [161]. One-pot epoxidation of alkenes can be achieved with hydrocarbons and $\mathrm{O}_{2}$ having tertiary hydrogen, provided that the proper catalyst combination and one initiator able to form organo Au species, which promotes the formation of the hydrocarbon hydro peroxides, are also present. It is possible to processed organic Au species on Au catalyst support over ceria by photolysis study but the processing of species based on Au peroxide can be derived from infra-ray (IR) studies through interaction of $\mathrm{O}_{2}$ and $\mathrm{Au}$ nanoparticles supported on $\mathrm{CeO}_{2}$ nanoparticles in the presence of AIBN promoter. These Au-peroxo species are responsible for oxygen to oxygen $(\mathrm{O}-\mathrm{O})$ transfer toward the hydrocarbon molecule adsorbed on the solid surface to produce the corresponding organic hydro peroxide which, after desorption, is used for alkene epoxidation. It is possible to achieve a rise in selectivity close to $100 \%$ during conversion of alkene in aerobic epoxidation of 1-octene more than it was achieved with two silylated order (Ti and Au catalyst with ceria support). The process, conveniently optimized, can be of interest for improving the efficiency of existing process for the synthesis of PO and which uses organic peroxides as oxidants, and more specifically cumene peroxide [165].

\subsubsection{Reaction path way of Propylene Epoxidation Au/ $\mathrm{CeO}_{2}$} Although only very few reports (previous or current) directly related to propylene epoxidation of $\mathrm{Au} / \mathrm{CeO} 2$ are available, some of the work demonstrated by few researchers most of which are based on theoretical simulations includes; the report of Chen Shilong et al on the reaction pathways of low-temperature CO oxidation on $\mathrm{Au} / \mathrm{CeO} 2$ catalyst. Through a comprehensive timeresolved Operando-DRIFTS study of the evolutions of various surface species on $\mathrm{Au} / \mathrm{CeO} 2$ catalysts with $\mathrm{Au}$ particle sizes ranging from $1.7 \pm 0.6$ to $3.7 \pm 0.9 \mathrm{~nm}$ during CO oxidation at room temperature, they showed the sizedependent reaction pathways and their contributions to the catalytic activity. According to this report, the types and concentrations of chemisorbed CO (a), carbonate, bicarbonate and formate species formed upon CO adsorption, their intrinsic oxidation reactivity toward $\mathrm{O}_{2}$ and roles in CO oxidation vary with the size of supported $\mathrm{Au}$ particles. They explained that the intrinsic oxidation reactivity of $\mathrm{CO}$ (a) does not depend much on the $\mathrm{Au}$ particle size whereas the intrinsic oxidation reactivity of carbonate, bicarbonate and formate species strongly 
depend on the Au particle size and are facilitated over $\mathrm{Au} / \mathrm{CeO} 2$ catalysts with large $\mathrm{Au}$ particles. Their work greatly advances the fundamental understanding of the effect of size of $\mathrm{Au} / \mathrm{CeO} 2$ catalysts for low-temperature CO oxidation and creates a way for further studies on the subject matter [166].

\subsubsection{Propylene Epoxidation $\mathrm{Au} / \mathrm{SiO}_{2}$}

Large number of environmental and industrial reactions requires the use of $\mathrm{Au}$ catalyst mostly with support making this catalyst a subject of discussion in research. This advancement is chiefly aligning with oxidation of propene to it oxide which was done in vapor phase in company of Au catalyst on $\mathrm{H}_{2}$ and $\mathrm{O}_{2}$ molecule, the central issue at hand is on how to employ distinct ways of making catalyst with appropriate support. The focal point here are; what significance does the catalyst preparation has?, what vital role does pretreatment method play?, what attributes does the support material acquire?, the size of the Au particle along with the amount of load are the center of attention. Possibilities to improve the catalyst productivity by employing promoters and by silylation are also discussed [167].

\subsubsection{Preparation of Catalysts}

Preparation of Meso-porous Ti-MCM-41 and Ti-MCM-48 supports was reported by hydrothermal crystallization process [168]. A modified sol-gel method was utilized to produce three-dimensional sponge-like mesoporous titanosilicates (designated, TiO-SiO) [169]. Ti grafting on TiMCM-41 support was done related to the reported procedures [170]. Extremely well arrayed Ti-containing mesoporous hybrid silsesquioxane were produced [171]. Impregnation approach was employed to process $\mathrm{Ti}$ support on non-porous silica [172]. Using DP approach Nano Au particles are deposited on its support [173, 174], employing aqueous solution of $\mathrm{HAuCl}_{4}$ with neutral $\mathrm{NaOH}$ as precipitant accompanied by air heating under temperature of 573 kelvin.

\subsubsection{Effect of Preparation Method and Pretreatment} Deposition-precipitation (DP) approach of synthesizing $\mathrm{Au}$ catalyst on Ti formed propene oxide with a maximum selectivity (100\%) and a very good conversion (1\%) rate under a good temperature condition of about 323 kelvin in company of $\mathrm{H}_{2} / \mathrm{O}_{2}$, this was a great breakthrough in the last 2-3 decades [173,175]. Catalysts that are not processed via DP approach are likely not to yield propene oxide. A point to note here is, only catalyst made through the above method can achieve propene oxide (figure 10). This method can deposit hemispherical Au nanoparticles only on the Ti sites of Ti-incorporated $\mathrm{SiO}_{2}$. A single product of $\mathrm{CO}_{2}$ is achieved when $\mathrm{Au}$ catalyst on double support (Ti-oxide/silicate) is made via impregnation [176]. The dilerence in product selectivity can be related to the state of dispersion and the connection structure of Au particles on model $\mathrm{TiO}_{2}$ support surface [177]. DP method deposits $\mathrm{Au}$ particles of about $2-5 \mathrm{~nm}$ in size on the support in a hemispherical shape, which are attached to the support at their flat planes; usually at plane $\{111\}$ (Figure 2) [177]. The effect of the contact structure is that the interface area of the particles of Au will be enclosed by large interval. On the contrary, small perimeter interface will be achieved when particles of $\mathrm{Au}>50 \mathrm{~nm}$ in diameter are stacked on support via impregnation. Maximum reactivity, reasonable efficiency of hydrogen was exhibited by $\mathrm{Au}$ catalyst on $\mathrm{Ti} / \mathrm{Si}$ which was made through operation of a precipitant specifically sodium hydroxide $(\mathrm{NaOH})$ [178], Urea, sodium hydrogen carbonate $\left(\mathrm{NaHCO}_{3}\right)$, sodium carbonate $\left(\mathrm{Na}_{2} \mathrm{CO}_{3}\right)$ and ammonia $\left(\mathrm{NH}_{3}\right)$. During DP of $\mathrm{Au}$ on titanosilicates it was observed that catalytic activity decreased with increasing severity of washing $[179,180]$, which might be probably caused by poor interactivity of $\mathrm{Au}$ and support resulting to moving away of Au from the surface of support. Partially charged Au nanoparticles are held on the support surface mostly due to electrostatic interaction with charged $\mathrm{Ti}$ sites while neutral silica surface cannot react with nanoparticles of $\mathrm{Au}$ [179]. The catalyst prepared from unwashed supported precipitate is found to have uniform sized and well-dispersed $\mathrm{Au}$ nanoparticles on the support (from TEM observation) showing the best activity [178]. Catalyst calcinations at around $573 \mathrm{~K}$ followed by pretreatment in dilute $\mathrm{H}_{2}$ stream and then dilute $\mathrm{O}_{2}$ streams at $523 \mathrm{~K}$ is necessary to obtain best catalysts performance [181, 169].

Propene epoxidation is a typical example for the novel catalysis of Au nanoparticles deposited on metal oxides.

\subsubsection{Reaction pathway of propylene epoxidaation $\mathrm{Au} /$ $\mathrm{SiO}_{2}$}

He Jieli et al report on the reaction pathway for the epoxidation of propylene by oxygen over $\mathrm{CuOx} / \mathrm{SiO}_{2}$ catalysts with and without $\mathrm{Cs}^{+}$modification. In their work, they report that $5 \mathrm{wt} \% \mathrm{CuOx} / \mathrm{SiO}_{2}$ catalysts was modified, which catalyst the formation of acrolein.

The kinetic studies explained that the acrolein and PO were formed in parallel as primary products via allylic 


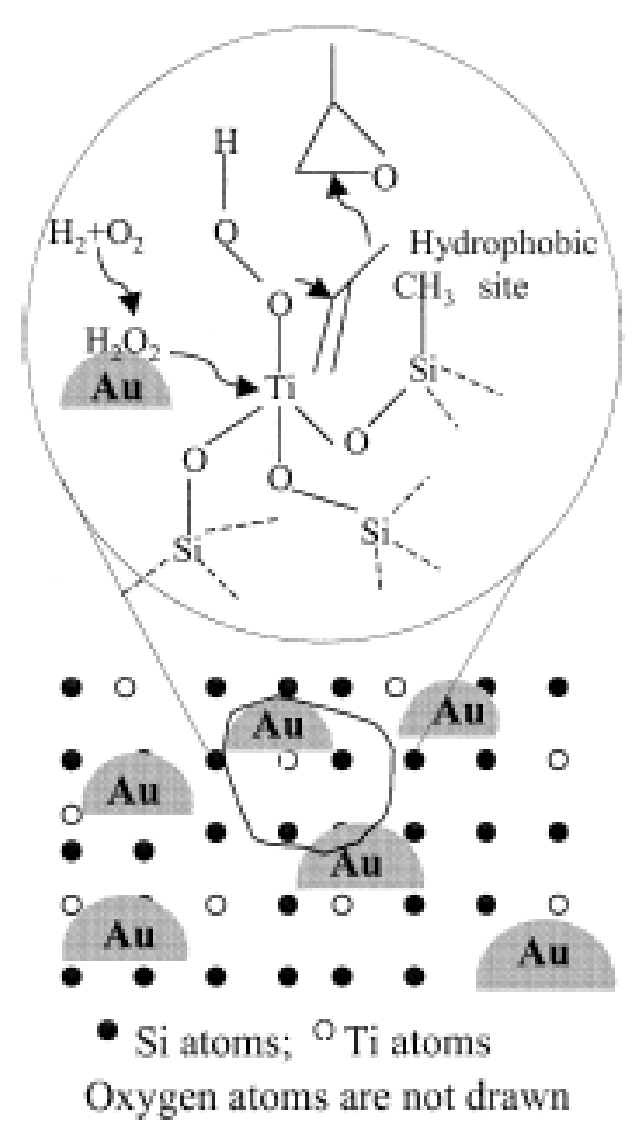

Figure 11: Influence of Au particle size on product yield during propene epoxidation using $\mathrm{O} 2$ and $\mathrm{H} 2$.

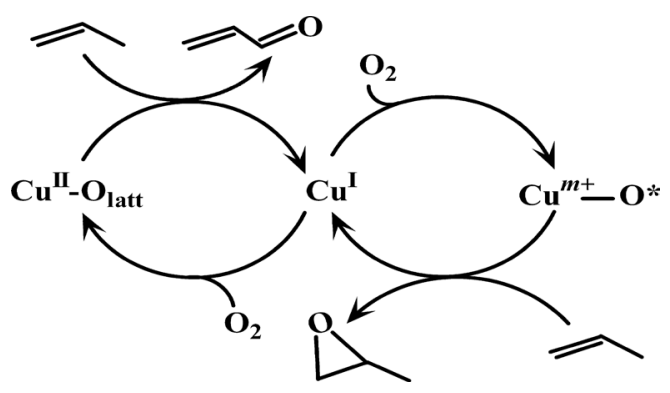

Figure 12: Proposed reaction mechanism for the formations of primary products over the $\mathrm{CuOx} / \mathrm{SiO} 2$ catalysts with and without $\mathrm{Cs}$ modification. $\mathrm{Cu}$ generated over the $\mathrm{CuOx} / \mathrm{SiO} 2$ catalyst with and without $\mathrm{Cs}$ modification during the reaction accounts for the formation of propylene oxide, while the lattice oxygen is responsible for acrolein formation. [182]

oxidation and epoxidation routes over the catalysts with and without $\mathrm{Cs}^{+}$modification. The PO undergoes isomerization into allyl alcohol and further oxidation into acrolein over the $5 \mathrm{wt} \% \mathrm{CuOx} / \mathrm{SiO}_{2}$ catalyst without $\mathrm{Cs}^{+}$modification. The modification by $\mathrm{Cs}^{+}$inhibited the consecutive conversion of PO by decreasing the acidity.
It was observed through pulse-reaction studies that the lattice oxygen species was responsible for the allylic oxidation of $\mathrm{C}_{3} \mathrm{H}_{6}$ to acrolein. Their report also showed that the lower reactivity of the lattice oxygen of the $\mathrm{Cs}^{+}$modified catalyst additionally contributed to the increase in PO selectivity. They proposed that $\mathrm{Cu}$ activated $\mathrm{O}_{2}$, thereby forming the active oxygen species for the conversion of $\mathrm{C}_{3} \mathrm{H}_{6}$ to PO. However, if the concentration of Cu sites is very high, this will not favor the selectivity of PO. The fig below is the proposed reaction mechanism for the formation of primary products over $\mathrm{CuOx} / \mathrm{SiO} 2$ catalysts with and without $\mathrm{Cs}^{+}$modification. [182]

\subsection{Methanol Synthesis}

Since the start of the last century, methanol $\left(\mathrm{CH}_{3} \mathrm{OH}\right)$ synthesis has attracted great interest because of its importance in chemical industries and its potential as an environmentally friendly energy carrier. The catalyst for the $\mathrm{CH}_{3} \mathrm{OH}$ synthesis has been a key area of research in order to optimize the reaction process. Several research on $\mathrm{CH}_{3} \mathrm{OH}$ synthesis by $\mathrm{Cu}$ have been reported because copper still remains the most active catalyst component even though the nature of the active site is yet to be fully understood. Recently, $\mathrm{CH}_{3} 3 \mathrm{OH}$ synthesis by various catalyst supports on metal oxide has been studied. This report gives an account of $\mathrm{CH}_{3} \mathrm{OH}$ synthesis by Au catalyst support on different metal oxide such as Ti, Si and Ce.

\subsubsection{Methanol Synthesis by Au/ZnO-TiO}

This study reports a synthesis of $\mathrm{CH}_{3} \mathrm{OH}$ by $\mathrm{Au} / \mathrm{ZnO}-\mathrm{TiO}_{2}$, $\mathrm{Au}$ which was deposited on some oxides with much dispersion was observed active when employed in $\mathrm{CO}_{2}$ hydrogenation ranging from $150-400^{\circ} \mathrm{C}$ temperatures. Characteristic features of support oxide determine the selectivity of the product. Elevated $\mathrm{CO}_{2}$ conversion rate with very low $\mathrm{CH}_{3} \mathrm{OH}$ rate is achieved with oxides that are acidic in nature for instance $\mathrm{TiO}_{2}$. Importantly, large particle size outcome of $\mathrm{Au}$ was observed and smaller $\mathrm{Au}$ particles gave higher $\mathrm{CH}_{3} \mathrm{OH}$ productivity per exposed surface area of $\mathrm{Au}$, which is because the particles of $\mathrm{Au}$ experience decrease in size due to increase in perimeter. Moreover, $\mathrm{CH}_{3} \mathrm{OH}$ was acquired from $\mathrm{Au}$ support on $\mathrm{Zn} /$ Ti because the interface of $\mathrm{Au} / \mathrm{Zn}$ becomes greater [183].

The combination of $\mathrm{ZnO}$ and $\mathrm{TiO}_{2}$ as oxide component was examined in more detail, because these catalysts gives $\mathrm{CH}_{3} \mathrm{OH}$ stability and selectively. From below fig. 12c it can be observed that the amount of zinc in oxide phase 
strongly determines the diameter of $\mathrm{Au}$ as well as the surface area of BET. The higher the zinc content, the lower the surface area of BET. There will be rise in the surface area of BET if magnesium citrate is introduced however, the presence of Ti in the content of the oxide will result to rise in the diameter of Au gotten from XRD studies. From the outcome of this work it is expressed that the nature of support oxide so much determines how active $\mathrm{CH}_{3} \mathrm{OH}$ can be in contrast to Au catalyst on a support, which can be explained as due to the interface site of both $\mathrm{Au}$ with it support which is very significant in the processing of $\mathrm{CH}_{3} \mathrm{OH}$ [184]. Production of $\mathrm{CH}_{3} \mathrm{OH}$ on the basis of selectivity significantly depends on the mixing together of the oxides of $\mathrm{Au} / \mathrm{Zn}$, but $\mathrm{ZnO}$ function is not well defined. A valuable means of creating Au particles of low size while enlarging the sites of its interface is via combining parts of the $\mathrm{TiO}_{2}$ in conjunction with magnesium citrate [185].

\subsubsection{Impact of Oxides Electronegativity}

Activity of $\mathrm{CO}_{2}$ is influenced by acidity of surface Fig. 13 expressed how the electronegativity of the oxides is related to $\mathrm{CO}_{2}$ conversion at $250^{\circ} \mathrm{C}$. The average size of $\mathrm{Au}$ particle in catalyst is insignificant, in relation with 5 $\mathrm{nm}$ except if the size of the Au is more than 5 for instance $10.5 \mathrm{~nm}$ size for Au catalysts on ceria support. The relatively acidic support, $\mathrm{TiO}_{2}$, revealed the highest $\mathrm{CO}_{2}$ conversion with basic support, $\mathrm{ZnO}$, the least. But small activity surface which is likely because $\mathrm{CO}_{2}$ is activated and adsorbed firmly onto the basic support. Maximum selectivity of $\mathrm{CH}_{3} \mathrm{OH} \mathrm{l}$ is favored by zinc support having the largest basicity

\subsubsection{Product Selectivity}

Fig.14a shows how the products are distributed over some typical $\mathrm{Au}$ catalysts. As described before, $\mathrm{Au} / \mathrm{TiO}_{2}$ gave the highest $\mathrm{CO}_{2}$ conversion, mostly at low temperatures. CO was the major product at this temperature range, which was obtained by reverse water gas shift reaction, and the yields obtained were very close to equilibrium. At temperatures above $350^{\circ} \mathrm{C}$, a large amount of $\mathrm{CH}_{4}$ was formed over $\mathrm{Au} / \mathrm{TiO}_{2}$ with selectivity exceeding $50 \%$. Selectivity of $\mathrm{Au}$ catalyst support by $\mathrm{Al}_{2} \mathrm{O}_{3}$ is comparable with Ti support, on the contrary, it $\mathrm{CO}_{2}$ conversion rate is small at certain temperature $\left(150^{\circ} \mathrm{C}\right)$ when compare with using Ti support. Over $\mathrm{Au} / \mathrm{ZnO}$ and $\mathrm{Au} / \mathrm{Fe}_{2} \mathrm{O}_{3}, \mathrm{CH}_{3} \mathrm{OH}$ was formed with relatively high selectivity in less than 30 atom $\%$ and supported on mixed oxides.

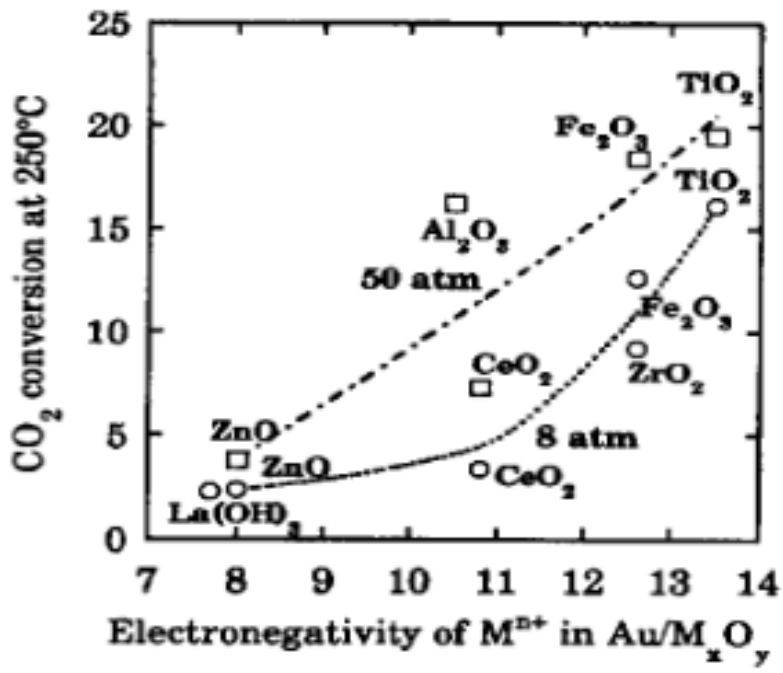

Figure 13: Impact of support oxides acidity in hydrogenation of $\mathrm{CO}_{2}$

\subsubsection{Combination of Oxides}

The relationship relating $\mathrm{CH}_{3} \mathrm{OH}$ production and selectivity at $250^{\circ} \mathrm{C}$ with reference to several Au catalysts having a metal loading with 33 atom $\%$ is shown in fig 12b. $\mathrm{CH}_{3} \mathrm{OH}$ whose selectivity is high was observed over $\mathrm{ZnO}$ which has $\mathrm{Au}$ catalysts. Oxides like $\mathrm{Fe}_{2} \mathrm{O}_{3}$ and $\mathrm{TiO}_{2}$ are added to $\mathrm{Au} / \mathrm{ZnO}$, chemicals gotten from $\mathrm{CH}_{3} \mathrm{OH}$ are enhanced, maintaining high selectivity exceeding that for commercial $\mathrm{Cu} / \mathrm{ZnO}-\mathrm{AI}_{2} \mathrm{O}_{3}$ catalyst. Although the $\mathrm{Au} /$ $\mathrm{ZnO}-\mathrm{Fe}_{2} \mathrm{O}_{3}$ catalyst confirmed the most elevated $\mathrm{CH}_{3} \mathrm{OH}$ yield and selectivity, the stability of the $\mathrm{CH}_{3} \mathrm{OH}$ yield at the reaction changed, depending on the pre-reduction conditions.

\subsubsection{Methanol Synthesis by $\mathrm{Au} / \mathrm{CeO}_{2}$}

There is only little report on $\mathrm{CH}_{3} \mathrm{OH}$ synthesis by $\mathrm{Au} /$ $\mathrm{CeO}_{2}$. E.A Shaw et al in their report examine the $\mathrm{CH}_{3} \mathrm{OH}$ synthesis activity of $\mathrm{Au} / \mathrm{CeO} 2$ catalysts derived by the oxidative activation of $\mathrm{CeAu}_{2}$ [186]. Boucher et al also gave a report on $\mathrm{CH}_{3} \mathrm{OH}$ synthesis over Au supported on $\mathrm{ZnO}$ and $\mathrm{CeO}_{2}$ Nano shapes. They investigate the active nature of $\mathrm{Au}$ clusters supported on $\mathrm{ZnO}$ and $\mathrm{CeO} 2 \mathrm{Nano}$ shapes produced by hydrothermal synthesis for the decomposition, oxidation, and steam reforming of $\mathrm{CH}_{3} \mathrm{OH}$ in their report, were $\mathrm{Au}$ atoms and clusters $(<1 \mathrm{~nm})$ were dispersed on the $\{110\}$ facets of $\mathrm{CeO} 2$ Nano rods, but only Au nanoparticles $(\sim 3 \mathrm{~nm})$ were found on the $\{100\}$ surfaces of CeO2 nanotubes. [187] 

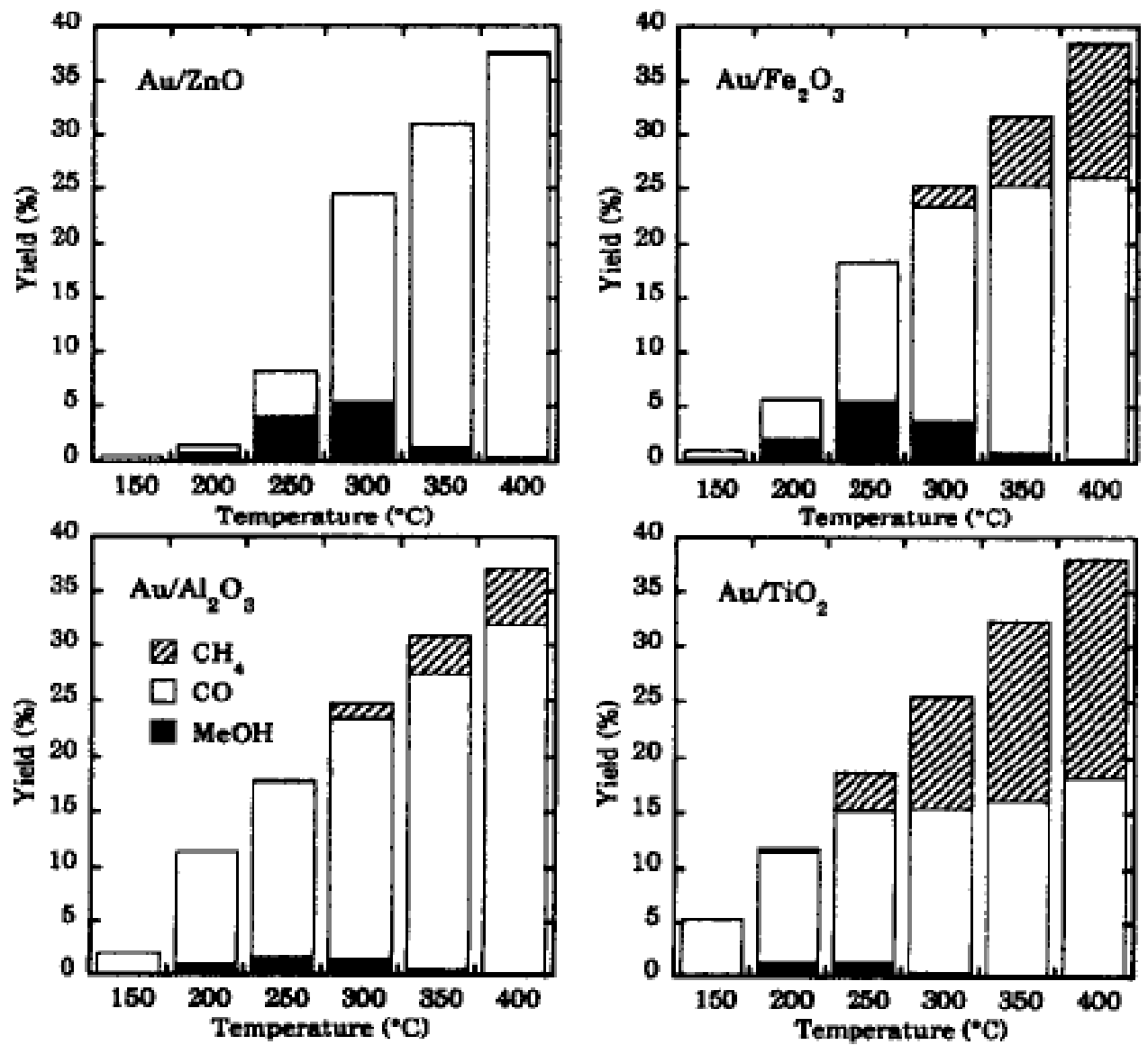

Figure 14a: Distribution of Product in hydrogenation of $\mathrm{CO} 2$ on Au catalyst with support

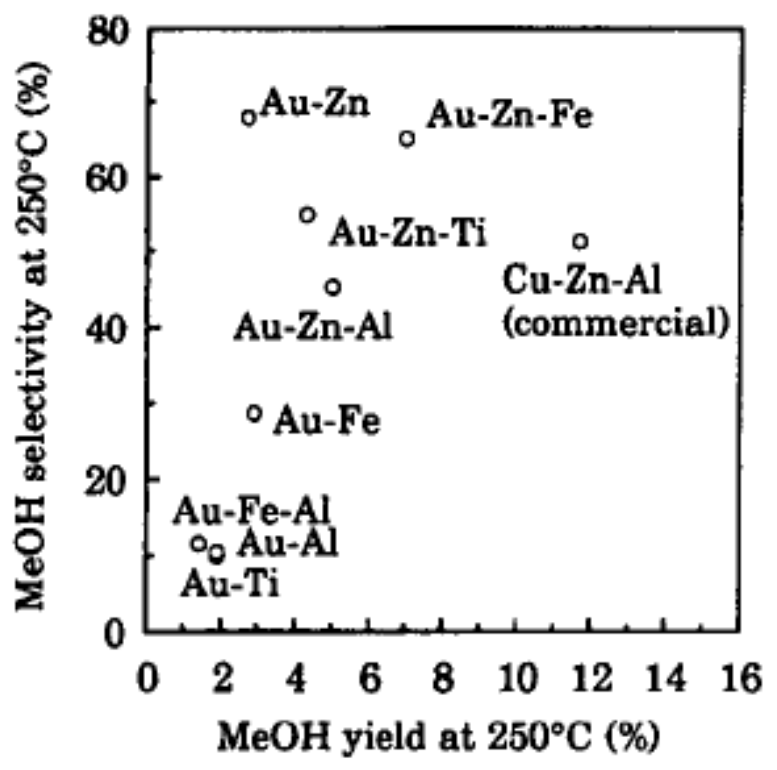

Figure 14b: correlation between $\mathrm{CH} 3 \mathrm{OH}$ yield and selectivity over $\mathrm{Au} / \mathrm{MOx} / \mathrm{MOy}$ (Au:M:M1=1:1:1 in atomic ratio

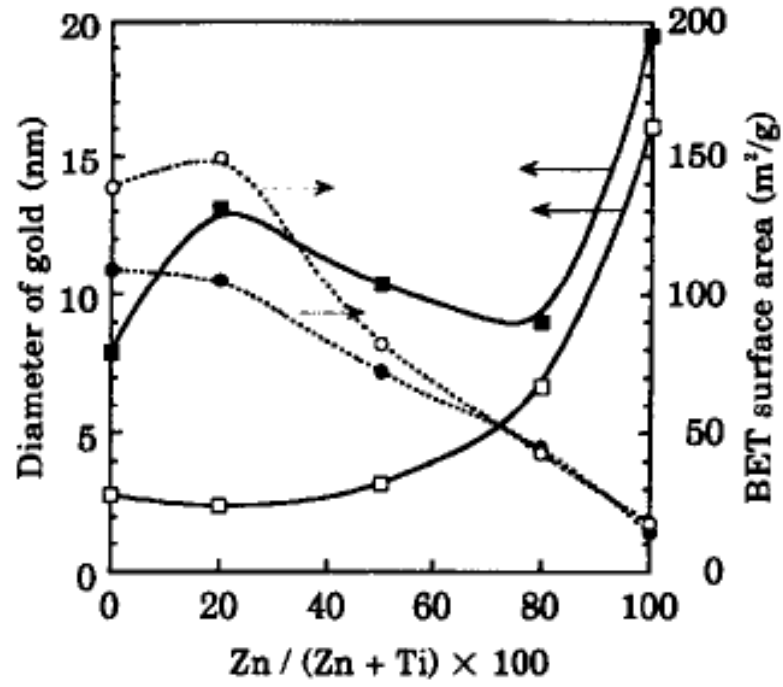

Figure 14c: $\mathrm{Zn}$ content in $\mathrm{Au} / \mathrm{ZnO}-\mathrm{TiO} 2$ as a determinant factor of surface area of BET and Au diameter. Prepared with Mg-citrate addition/prepared without $\mathrm{Mg}$-citrate addition 


\subsubsection{Mechanism of methanol synthesis over $\mathrm{Au} / \mathrm{CeO}$} This is according to the work of Basin $\mathrm{P}$ et al, who proposed a kinetic model providing the order, kinetic constants and the activation energy for the methanol oxidation mechanism over $\mathrm{Au} / \mathrm{CeO} 2$ catalyst through complementary kinetic and FTIR (Fourier transform infrared spectroscopy) operando SSITKA (steady-state isotopic transient kinetic analysis) approaches. They studied Au-supporting oxide with high catalytic activity at room temperature towards combustion of methanol as a model VOC (volatile organic compound); they employed complementary kinetic and FTIR operando SSITKA approaches which give them access to investigate the mechanism of the reaction. According to the kinetic model which they proposed for the reaction, they discovered that; methanol adsorbs via dissociation on the surface of Ce forming methoxys, linearly and bridged adsorbed methoxys act as an intermediates, transforming then into formates (only in presence of $\mathrm{Au}$ in the considered low temperature range), while other types of methoxy species are spectators, formates, whose transformation was found (considering their thermal behavior) to be the rate determining step (RDS) for the reaction, decompose into $\mathrm{CO}$ and $\mathrm{OH}$ species, this decomposition only takes place in the area of the Au NPs (in a zone identified as an "active perimeter"), where $\mathrm{Au}$ oxidizes adsorbed $\mathrm{CO}$ to $\mathrm{CO}_{2}$. The reaction model can thus be represented by the following set of five successive elemental steps.

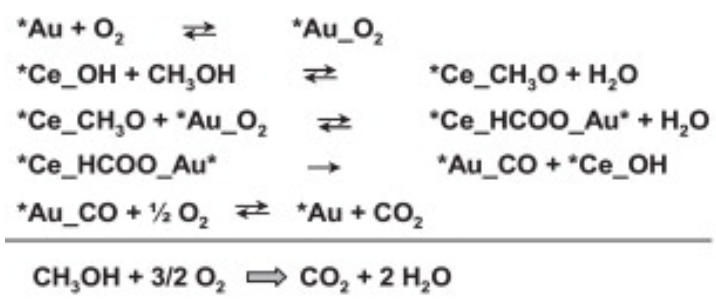

Where ${ }^{\star} \mathrm{Au}$ and ${ }^{\star} \mathrm{Ce}$ are superficial active sites, $K_{1}, K_{2}$ are adsorption equilibrium constants and $K_{3}, K_{5}$ are equilibrium constants for steps 3 and 5 respectively.

They assume that the formate decomposition is the rate determining step and hence, the model is then proposed which was further realized through the SSITKA experiment which also gives room for the determination of the activation energy associated to the RDS. The value which they obtained from the SSITKA analysis is some extend less than the apparent activation energy and the difference between the values is consistent with the proposed kinetic model. [188]

\subsubsection{Methanol Synthesis by $\mathrm{Au} / \mathrm{SiO}_{2}$}

This gives a description of a chemical process making use of $\mathrm{Au}$ nanoparticle that serve as a catalyst along with ionic liquids (IL) as solvent for methane $\left(\mathrm{CH}_{4}\right)$ oxidation as reported by ( $\mathrm{T} \mathrm{Li}$ et al.). This was how the reaction took place; 100ml autoclave was charged with the following catalyst, solvent, acid reagent, oxidant altogether and accordingly $\left(\mathrm{Au} / \mathrm{SiO}_{2}, \mathrm{Cl}\right.$, trifluoroacetic anhydride/ trifluoroacetic acid, $\mathrm{K}_{2} \mathrm{~S}_{2} \mathrm{O}_{8}$ ). Influence of the catalyst $(0.01 \mathrm{~g}) / \mathrm{IL}(1 \mathrm{~g})$ during $\mathrm{CH}_{4}$ conversion was reviewed at about 90 degrees temperature while the prime product obtained was $\mathrm{CH}_{3} \mathrm{OH}$. The outcome obtained in \% from the above reaction involving both IL and catalysts were as follows; $24.9 \%$ obtained during conversion of $\mathrm{CH}_{4}$, $71.5 \%$ obtained as product selectivity with $17.8 \%$ yield. $\%$ selectivity of $\mathrm{CO}_{2}$ is 16 with a yield of $0.6 \%$, while $\mathrm{H}_{2}$ has a selectivity of $0.4 \%$ and yields $0.1 \%$. Salvaging of both the catalyst and IL in the reactor will retrieve 96.9 in \%. The mechanism associated with the transformation of $\mathrm{CH}_{4}$ to $\mathrm{CH}_{3} \mathrm{OH}$, including the action of the Nano Au catalyst, was also discussed. [189]

\subsubsection{Impact of Nano-Au/Sio ${ }_{2}$ Catalyst on $\mathrm{CH}_{4}$ Conversion}

Over the years the effectiveness of this catalyst in $\mathrm{CH}_{4}$ conversion has been tremendous. The outcome reveals that, when no Nano- $\mathrm{Au} / \mathrm{SiO}_{2}$ was found in the reaction system, no conversion of $\mathrm{CH}_{4}$ could be detected. With an increase in the amount of $\mathrm{Nano} \mathrm{Au} / \mathrm{SiO}_{2}$ in the reaction system, the conversion rate, selectivity, and yield increased correspondingly. As the amount of the Nano-Au/ $\mathrm{SiO}_{2}$ reached $0.01 \mathrm{~g}$, the conversion rate, selectivity, and yield increased to $24.85 \%, 71.5 \%$, and $17.8 \%$. Further addition of the Nano- $\mathrm{Au} / \mathrm{SiO}_{2}$ catalyst increased the selectivity limitedly, but lowered the conversion rate and yield rapidly. One possible reason is that, as the level of the Nano- $\mathrm{Au} / \mathrm{SiO}_{2}$ was further increased, side reactions will become more significant and this will accelerate the exchange of the anions of trifluoroacetic acid with the anions of the IL, which will then lead to a decrease in the acidity of the reaction system, thus decreasing the $\mathrm{CH}_{4}$ conversion rate and yield dramatically. Over the catalyst system of Nano-Au ( $\left.\mathrm{Au} / \mathrm{SiO}_{2}\right)$ and IL, the process of $\mathrm{CH}_{4}$ to $\mathrm{CH}_{3} \mathrm{OH}$ was investigated. The significance of the IL as reveal from the effect of this study cannot be overemphasize as it stimulates $\mathrm{Au}$ catalyst activity and at the same time enables dissolution, moreover exhibit a reaction with high selectivity. The system of $\mathrm{Nano}-\mathrm{Au} / \mathrm{SiO}_{2}$ and IL could be recycled, and conversion of $\mathrm{CH}_{4}$ in the recycled system 
still remained at a high level. There are no environmental implications as regards this technique of oxidation of $\mathrm{CH}_{4}$ as heavy metals/undiluted Sulfuric acid and other environmentally harmful chemicals were not involved during the reaction. A reaction mechanism was proposed, which indicate that molecular oxygen got consumed in the oxidation-reduction cycle. Consequently, $\mathrm{CH}_{4}$ oxidation to $\mathrm{CH}_{3} \mathrm{OH}$ can be achieved as a green chemical process. The system can also be employed in other green chemical processes of liquid phase or gas phase oxidation.

\section{Conclusions and Future Perspective}

Remarkably, activities of catalysts having a high degree of support $\mathrm{Au}$ catalysts for $\mathrm{CO}$ oxidation under room temperature arises from reaction of $\mathrm{CO}$ absorbed on the step, the extreme which is the edge, and also the corner of nanoparticles of Au catalyst on oxide support where molecules of oxygen are adsorbed at it circumference area. It is unlikely that oxide Au species and non-metallic small $\mathrm{Au}$ clusters are brain behind the extraordinarily high catalytic activity, although they are active to a certain extent. It is proposed that epoxidation of propylene proceeds by the formation of $\mathrm{H}_{2} \mathrm{O}_{2}$ on the surfaces of $\mathrm{Au}$ particles, capture as $\mathrm{OOH}$ at $\mathrm{Ti}^{4+}$ in tetrahedral coordination in the matrices of $\mathrm{SiO}_{2}$, which include uptake of propylene on the surfaces of the oxide support in the process of $\mathrm{OOH}$ reaction. Over the catalyst system of Nano-gold $\left(\mathrm{Au} / \mathrm{SiO}_{2}\right)$ and IL, the process of $\mathrm{CH}_{4}$ to $\mathrm{CH}_{3} \mathrm{OH}$ was investigated. The significance of IL as reveal from the effect of this study cannot be overemphasize as it stimulates $\mathrm{Au}$ catalyst activity and at the same time enables dissolution, moreover exhibit a reaction with high selectivity. The system of $\mathrm{Nano}-\mathrm{Au} / \mathrm{SiO}_{2}$ and IL could be recycled, and conversion of $\mathrm{CH}_{4}$ in the recycled system still remained at a high level. There are no environmental implications regarding this system of oxidation of $\mathrm{CH}_{4}$ since heavy metals along with undiluted Sulfuric acid and other environmentally harmful chemicals was not involved during the reaction. A reaction mechanism was proposed, which indicated that molecular oxygen was consumed in the oxidationreduction cycle. Consequently, $\mathrm{CH}_{4}$ oxidation $\mathrm{CH}_{3} \mathrm{OH}$ can be achieved as a green chemical process. The system can also be used in other green chemical processes of liquid phase or gas phase oxidation.

$\mathrm{CH}_{3} \mathrm{OH}$ is expected to be a potential solution to the partial deployment of fossil source-based economies. Moreover, it is a recognized energy carrier that is better than other alternatives in terms of transportation, storage and reuse. New or improved catalysts for $\mathrm{CH}_{3} \mathrm{OH}$ production are likely to be discovered in the near future. These catalytic materials are expected to allow lowering the temperature and pressure required for the $\mathrm{CH}_{3} \mathrm{OH}$ synthesis reaction. With pressure still useful to favor the reaction that is limited by the thermodynamic equilibrium, the current temperature of the $\mathrm{CH}_{3} \mathrm{OH}$ synthesis process is over the Huttig temperature, thus promoting the catalyst sintering.

Acknowledgement: Because we are a team of up-coming researchers, we do not have any available sources of funding from any external funding organization.

Conflict of Interest: The author's declare no conflict of interest

\section{References}

[1] B. Hammer, J.K. Norskov, Nature 376 (1995) 238.

[2] M. Haruta, N. Yamada, T. Kobayashi, S. Iijima, J. Catal. 115 (1989) 301.

[3] M. Haruta, S. Tsubota, T. Kobayashi, H. Kageyama, M.J. Genet, B. Delmon, J. Catal. 144 (1993) 175

[4] Haruta, M.; Kobayashi, T.; Sano, H.; Yamada, N. Novel gold catalysts for the oxidation of carbon monoxide at a temperature below 0 国. Chem. Lett. 1987, 16, 405-408. [CrossRef]

[5] . Bond, G.C.; Thompson, D.T. Catalysis by gold. Catal. Rev.Sci. Eng. 1999, 41, 319-388. [CrossRef]

[6] Lopez, N.; Janssens, T.V.; Clausen, B.S.; Xu, Y.; Mavrikakis, M.; Bligaad, T.; Nørskov, J.K. On the origin of the catalytic activity of gold nanoparticles for low-temperature CO oxidation. J. Catal. 2004, 223, 232-235. [CrossRef]

[7] Liu, X.L.; Wang, A.; Zhang, T.; Mou, C.-Y. Catalysis by gold: New insights into the support effect. Nano Today 2013, 8, 403-416. [CrossRef]

[8] Casaletto, M.P.; Longo, A.; Venezia, A.M.; Mortorana, A.; Prestianni, A. Metal-support and preparation influence on the structural and electronic properties of gold catalysts. Appl. Catal. A Gen. 2006, 302, 309-316. [CrossRef]

[9] Socha, R.P.; Zackiewicz, E.; Spiridis, N.; Korecki, J. Au adsorption on defect-rich $\mathrm{MgO}(100)$ surfaces. Surf. Interface Anal. 2010, 42, 536-539. [CrossRef]

[10] Gutiérrez, L.-F.; Hamoudi, S.; Belkacemi, K. Synthesis of gold catalysts supported on mesoporous silica materials: Recent developments. Catalysts 2011, 1, 97-154. [CrossRef]

[11] Mizera, J.; Spiridis, N.; Socha, R.; Grabowski, R.; Samson, K.; Korecki, J.; Grzybowska, B.; Gurgul, J.; K „epi ‘nski, L.; Matecka, M.A. Au/FeOx catalysts of different degree of iron oxide reduction. Catal. Today 2012, 187, 20-29. [CrossRef]

[12] Moreau, F.; Bond, G.C.; Linden, B.J. van der; Silberova, B.; Makkee, M. Gold supported on mixed oxides for the oxidation 
of carbon monoxide. Appl. Catal. B Environ. 2008, 347, 208-215. [CrossRef]

[13] Zheng, N.F.; Stucky, G.D. A general synthetic strategy for oxide-supported metal nanoparticle catalysts. J. Am. Chem. Soc. 2006, 128, 14278-14280.

[14] Guzman, J.; Gates, B.C. Catalysis by supported gold: Correlation between catalytic activity for $\mathrm{CO}$ oxidation and oxidation states of gold. J. Am. Chem. Soc. 2004, 126, 2672-2673.

[15] Haruta, M. Catalysis of gold nanoparticles deposited on metal oxides. Cattech 2002, 6, 102-115.

[16] Ma, Z.; Overbury, S.H.; Dai, S. Gold nanoparticles as chemical catalysts. In Nanomaterials: Inorganic and Bioinorganic Perspectives; Lukehart, C.M., Scott, R.A., Eds.; John Wiley \& Sons: Chichester, UK, 2008; pp. 247-266.

[17] M. Casaletto, A. Longo, A. Martorana, A. Prestianni, A. Venezia, XPS study of supported gold catalysts: the role of $A u 0$ and $A u+\delta$ species as active sites, Surface and interface analysis, 38 (2006) 215-218.

[18] M.M. Schubert, S. Hackenberg, A.C. van Veen, M. Muhler, V. Plzak, R.J. Behm, CO Oxidation over supported gold catalysts-"inert" and "active" support materials and their role for the oxygen supply during reaction, Journal of Catalysis, 197 (2001) 113- 122

[19] S. Minicò, S. Scirè, C. Crisafulli, A.M. Visco, S. Galvagno, FT-IR study of $\mathrm{Au} / \mathrm{Fe} 2 \mathrm{O} 3$ catalysts for $\mathrm{CO}$ oxidation at low temperature, Catal Lett, 47 (1997) 273-276.

[20] 20. G.C. Bond, Introduction to the physical and chemical properties of gold, in: Gold Nanoparticles for Physics, Chemistry and Biology, Imperial College Press, London, 2012, pp. 29-42.

[21] S. Shaikhutdinov, Surface structures of gold nanoparticles, in: Gold Nanoparticles for Physics, Chemistry and Biology, Imperial College Press, London, 2012, pp. 199-231

[22] Catalysis by Ceria and Related Materials; Trovarelli, A., Ed.; Imperial College Press: London, 2002.

[23] Alberto Sandoval1, Antonio Gómez-Cortés2, Rodolfo Zanella1*, José M. Saniger1, Gabriela Díaz2* 04510, México 2Instituto de Física, UNAM, A. P. 20-364 México D. F. 01000 México.

[24] Nazila Masoud, Laurent Delannoy, Herrick Schaink, Ad van der Eerden, Jan Willem de Rijk, Tiago A. G. Silva Banerjee, Johannes D. Meeldijk, Krijn P. de Jong ${ }^{\dagger}$, Catherine Louis $^{\ddagger}$, and Petra E. de Jongh ${ }^{*+}$ Superior Stability of Au/ $\mathrm{SiO}_{2}$ Compared to $\mathrm{Au} / \mathrm{TiO}_{2}$ Catalysts for the Selective Hydrogenation of Butadiene. ACS Catal., 2017, 7 (9), pp 5594-5603

[25] By Ziyauddin S. Qureshi and EA Jaseer. Silica-Supported Gold Nanocatalyst for CO Oxidation. Published February 13th 2019 DOI: 10.5772 /intechopen.80620.

[26] Daniel Widmann and R. Jrgen Behm. Active Oxygen on a Au/ TiO2 Catalyst: Formation, Stability, and CO Oxidation Activity. Angew. Chem. Int. Ed. 2011, 50, 10241-10245.

[27] Rodolfo Zanella,† Suzanne Giorgio, $¥$ Claude R. Henry, $¥$ and Catherine Louis*,Alternative Methods for the Preparation of Gold Nanoparticles Supported on TiO2. J. Phys. Chem. B 2002, 106, 7634-7642.

[28] Bahareh A.T. Mehrabadi Sonia Eskandari, Umema Khan, Rembert D. White, John R. Regalbuto. A Review of Preparation
Methods for Supported Metal Catalysts. Advances in Catalysis Volume 61, 2017, Pages 1-35

[29] M. Haruta, T. Kobayashi, H. Sano, N. Yamada, Novel gold catalysts for the oxidation of carbon monoxide at a temperature far below $0^{\circ} \mathrm{C}$, Chemistry Letters, 16 (1987) 405408.

[30] H. Masatake, D. Masakazu, Advances in the catalysis of Au nanoparticles, Applied Catalysis A: General, 222 (2001) 427-437.

[31] A. Wolf, F. Schüth, A systematic study of the synthesis conditions for the preparation of highly active gold catalysts, Applied Catalysis A: General, 226 (2002) 1-13.

[32] S. Minicò, S. Scirè, C. Crisafulli, A.M. Visco, S. Galvagno, FT-IR study of $\mathrm{Au} / \mathrm{Fe} 2 \mathrm{O} 3$ catalysts for $\mathrm{CO}$ oxidation at low temperature, Catal Lett, 47 (1997) 273-276.

[33] M. Haruta, S. Tsubota, T. Kobayashi, H. Kageyama, M.J. Genet, B. Delmon, LowTemperature Oxidation of CO over Gold Supported on TiO2, $\alpha$-Fe203, and Co304, Journal of Catalysis, 144 (1993) 175-192.

[34] G. Bond, D. Thompson, Gold-catalysed oxidation of carbon monoxide, Gold Bull, 33 (2000) 41-50.

[35] T.V. Choudhary, D.W. Goodman/Oxidation catalysis by supported gold nano-clusters

[36] B.Viswanathan, Catalysis by Nanoparticles, Shape and size dependence, Chapter Nanoparticles for catalysis, energy and drug delivery, Eds. Ramesh S. Chaughule and Anant R Kapdi, American Scientific Publishers, (2014).

[37] Haruta, M. Catalysis Today 1997, 36, 153.

[38] Mills, G.; Gordon, M. S.; Metiu, H. Chemical Physics Letters 2002, 359, 493

[39] Wu, X.; Senapati, L.; Nayak, S. K.; Selloni, A.; Hajaligol, M. Journal of Chemical Physics 2002, 117, 4010.

[40] Beien Zhu, Gode Thrimurthulu, Journal of Catalysis 308 (2013) 272-281

[41] Rajesh Sardar, Alison M. Funston and Royce W. Murray, Langmuir 25 (2009), 13840-13851.

[42] Andrew A. Herzing, Christopher J. Kiely, and Albert F. Carley, Science,321 (2008) 1331-1335

[43] Yong Liu, Chun-Jiang Jia and Ferdi Schuth, Angew. Chem. Int. Ed.49 (2010)5771-5775.

[44] Zhi Li, Cristian V. Ciobanu and Ryan Richards Phys. Chem. Chem. Phys, 13 45(2011) 2582-2589.

[45] Nippon Shokubai Co. Ltd., Jpn. Pat. Pub. No. H10-244156, Intern. Pub. No. W097/34692; Dow Chemical Co., Intern. Pub. No. W098/00413, W098/00414, W098/00415; Bayer AG, DE $19804712 \mathrm{~A} 1$

[46] M. Haruta, B.S. Uphade, S. Tsubota, A. Miyamoto, Res. Chem. Intermed. 24 (1998) 329.

[47] B.S. Uphade, S. Tsubota, T. Hayashi, M. Haruta, Chem. Lett. 1277 (1998)

[48] Y.A. Kalvachev, T. Hayashi, S. Tsubota, M. Haruta, J. Catal. 186 (1999) 228

[49] B.S. Uphade, Y. Yamada, T. Nakamura, M. Haruta, Appl. Catal. A: Gen. 215 (2001) 137.

[50] C.Qi.T. Akita, M. Okumura, M. Haruta, Appl. Catal. A: Gen. 218 (2001) 81.

[51] T.A. Nijhuis, B.J. Huizinga, M. Makkee, J.A. Moulijn, Ind. Eng. Chem. Res. 38 (1999) 884

[52] E.E. Stangland, K.B. Stavens, R.P. Andres, W.N. Delgass, J. Catal. 191 (2000) 332. 
[53] G. Mul, A. Zwijnenburg, B. Linden, M. Makkee, J.A. Moulijn, J. Catal. 3239 (2001)

[54] B.S. Uphade, T. Akita, T. Nakamura, M. Haruta, J. Catal., submitted for publication.

[55] T. Hayashi, K. Tanaka, M. Haruta, J. Catal. 178 (1998) 566

[56] K.A. Davis, D.W. Goodman, J. Phys. Chem. B 104 (2000) 8557

[57] J. B. Hansen and P. E. Højlund Nielsen, Handbook of Heterogeneous Catalysis, Wiley VCH, 2008, vol. 13.13, p. 2920.

[58] X. Xu and J. A. Moulijn, Energy Fuels, 1996, 10, 305.

[59] A. J. Hunt, E. H. K. Sin, R. Marriott and J. H. Clark, ChemSusChem, 2010, 3, 306.

[60] M.Aresta,inActivation of Small Molecules, ed. W.B.Tolman, 2006, vol. 1, p. 1.

[61] A. Goeppert, M. Czaun, J. P. Jones, G. S. Prakash and G. A. Olah, Chem. Soc. Rev., 2014, 43, 7995.

[62] The George Olah Renewable Methanol Plant, 2009, www. carbonrecycling.is.

[63] K. Klier, Adv. Catal., 1982, 31, 243.

[64] L. C. Grabow and M. Mavrikakis, ACS Catal., 2011, 1, 365.

[65] E. L. Kunkes, F. Studt, R. Schlo "gl, F. Abild-Pedersen and M. Behrens, J. Catal., 2015, 328, 43.

[66] O. Martin, C. Mondelli, D. Curulla-Ferre', C. Drouilly, R. Hauert and J. Perez-Ramirez, ACS Catal., 2015, 5, 5607

[67] J. Sloczynski, R. Grabowski, A. Kozlowska, P. Olszewski, J. Stoch, J. Skrzypek and M. Lachowska, Appl. Catal., A, 2004, 278, 11. .

[68] X.-L. Liang, X. Dong, G.-D. Lin and H.-B. Zhang, Appl. Catal., B, 2009, 88, 315

[69] Y. Hartadi, D. Widmann and R. J. Behm, ChemSusChem, 2015, 8, 456.

[70] N. Y. Topsøe and H. Topsøe, Top. Catal., 1999, 8, 267.

[71] C. Tisseraud, C. Comminges, T. Belin, H. Ahouari, A. Soualah, Y. Pouilloux and A. Le Valant, J. Catal., 2015, 330, 533.

[72] Catalysis by Ceria and Related Materials; Trovarelli, A., Ed.; Imperial College Press: London, 2002

[73] Bourane, A.; Bianchi, D. J. Catal. 2001, 202, 34.

[74] Wojciechowski, B. W.; Aspey, S. P. Appl. Catal. A: Gen. 2000, $190,1$.

[75] Langmuir, I. Trans. Faraday Soc. 1922, 17, 621

[76] A.I. Kozlov, A.P. Kozlova, H. Liu, Y. Iwasawa, Appl. Catal. A: Gen. 182 (1999) 9.

[77] G.C. Bond, D.T. Thompson, Au Bull. 33 (2000) 41.

[78] F. Cosandey, T.E. Madey, Surf. Rev. Lett. 8 (2001) 73.

[79] M.A.P. Dekkers, M.J. Lippits, B.E. Nieuwenhuys, Catal. Lett. 56 (1998) 195.

[80] F. Boccuzzi, A. Chiorino, M. Manzoli, P. Lu, T. Akita, S. Ichikawa, M. Haruta, J. Catal. 202 (2001) 256.

[81] M. Mavrikakis, P. Stoltze, J.K. Nørskov, Catal. Lett. 64 (2000) 101.

[82] M. Valden, X. Lai, D.W. Goodman, Science 281 (1998) 1647.

[83] F. Boccuzzi, A. Chiorino, M. Manzoli, Surf. Sci. 942 (2000) 454.

[84] J.D. Grunwaldt, C. Kiener, C. Wögerbauer, A. Baiker, J. Catal. 181 (1999) 223.

[85] J.D. Grunwaldt, A. Baiker, J. Phys. Chem. B 103 (1999) 1002.

[86] S. Tsubota, T. Nakamura, K. Tanaka, M. Haruta, Catal. Lett. 56 (1998) 131.

[87] Y. lizuka, T. Tode, T. Takao, K. Yatsu, T. Takeuchi, S. Tsubota, et al., J. Catal. 187 (1999) 50.
[88] M. Haruta, M. Daté, Y. lizuka, F. Boccuzzi, Shokubai (Catalysts and Catalysis) 43 (2001) 125.

[89] T. Akita, K. Tanaka, S. Tsubota, M. Haruta, J. Electron Microsc. $49(2000) 657$.

[90] T. Akita, P. Lu, S. Ichikawa, K. Tanaka, M. Haruta, Surf. Interface Anal. 31 (2001) 73.

[91] N.J. Ossipoff, N.W. Cant, Topics Catal. 8 (1999) 161. [32] M. Daté, M. Haruta, J. Catal. 201 (2001) 221.

[92] M. Daté, M. Haruta, J. Catal. 201 (2001) 221.

[93] Avgouropoulos, G.; loannides, T. Selective CO oxidation over $\mathrm{CuO}-\mathrm{CeO} 2$ catalysts prepared via the urea-nitrate combustion method. Appl. Catal. A 2003, 244, 155-167. [CrossRef]

[94] Trimm, D.L. Minimisation of carbon monoxide in a hydrogen stream for fuel cell application. Appl. Catal. A 2005, 296, 1-11. [CrossRef]

[95] Chen, M.S.; Goodman, D.W. Structure-activity relationships in supported Au catalysts. Catal. Today 2006, 111, 22-33. [CrossRef]

[96] Romero-Sarria, F.; Dominguez, M.I.; Centeno, M.A.; Odriozola, J.A. CO oxidation at low temperature on $\mathrm{Au} / \mathrm{CePO} 4$ : Mechanistic aspects. Appl. Catal. B 2011, 107, 268-273. [CrossRef]

[97] Corma, A.; García, H. Supported gold nanoparticles as oxidation catalysts. In Nanoparticles and Catalysis; Astruc, D., Ed.; Willey-VCH Verlag GmbH \& Co. KGaA: Weinheim, Germany, 2008; pp. 389-429.

[98] Trovarelli, A. Catalytic properties of ceria and $\mathrm{CeO} 2$ -containing materials. Catal. Rev. Sci. Eng. 1996, 38, 439-520. [CrossRef]

[99] Laguna, O.H.; Sarria, F.R.; Centeno, M.A.; Odriozola, J.A. Gold supported on metal-doped ceria catalysts $(M=Z r, Z n$ and $\mathrm{Fe}$ ) for the preferential oxidation of CO (PROX). J. Catal. 2010, 276, 360-370. [CrossRef]

[100] Bond, G.C.; Louis, C.; Thompson, D.T. Catalysis by gold. In Catalytic Science Series; Hutchings, G.J., Ed.; Imperial College Press: London, UK, 2006; pp. 180-182

[101] Fu, Q.; Saltsburg, H.; Flytzani-Stephanopoulos, M. Active nonmetallic Au and Pt species on ceria-based water-gas shift catalysts. Science 2003, 301, 935-938. [CrossRef] [PubMed]

[102] Wahlström, E.; Lopez, N.; Schaub, R.; Thostrup, P.; Ronnau, A.; Africh, C.; Laegsgaard, E.; Norskov, J.K.; Besenbacher, F. Bonding of gold nanoclusters to oxygen vacancies on rutile TiO2 (110). Phys. Rev. Lett. 2003. [CrossRef] [PubMed]

[103] Guzman, J.; Carrettin, S.; Fierro-Gonzalez, J.C.; Hao, Y.L.; Gates, B.C.; Corma, A. CO oxidation catalyzed by supported gold: Cooperation between gold and nanocrystalline rare-earth supports forms reactive surface superoxide and peroxide species. Angew. Chem. Int. Ed. 2005, 44, 47784781. [CrossRef] [PubMed]

[104] Wuilloud, E.; Delley, B.; Schneider, W.D.; Baer, Y. Spectroscopic evidence for localized and extended F-symmetry states in CeO2 . Phys. Rev. Lett. 1984, 53, 202-205. [CrossRef]

[105] Binet, C.; Badri, A.; Lavalley, J.C. A spectroscopic characterization of the reduction of ceria from electronic transitions of intrinsic point-defects. J. Phys. Chem. 1994, 98, 6392-6398. [CrossRef]

[106] Sudarsanam, P.; Mallesham, B.; Reddy, P.S.; Großmann, D.; Grünert, W.; Reddy, B.M. Nano-Au/CeO2 catalysts for 
CO oxidation: Influence of dopants (Fe, La and Zr) on the physicochemical properties and catalytic activity. Appl. Catal. B 2014, 144, 900-908. [CrossRef]

[107] JIA M L et al., Preparation of $\mathrm{Au} / \mathrm{CeO} 2$ catalyst and its catalytic performance for $\mathrm{HCHO}$ oxidation, june 2007. journal of rare earths, Vol. 26, No. 4, Aug. 2008, p. 528

[108] Miedziak, P.J.; Tang, Z.; Davies, T.E.; Enache, D.I.; Bartley, J.K.; Carley, A.F.; Herzing, A.A.; Kiely, C.J.; Taylor, S.H.; Hutchings, G.J. Ceria prepared using supercritical anti solvent precipitation: A green support for gold-palladium nanoparticles for the selective catalytic oxidation of alcohols. J. Mater. Chem. 2009, 19, 8619-8627. [CrossRef]

[109] Qu,Y.H.;Liu,F.;Wei,Y.;Gu,C.L.;Zhang,L.H.;Liu,Y. FormingceriashellonAu-corebyLSPRphotothermal induced interface reaction. Appl. Surf. Sci. 2015, 343, 207-211. [CrossRef]

[110] Mitsudome, T.; Yamamoto, M.; Maeno, Z.; Mizugaki, T.; Jitsukawa, K.; Kaneda, K. One-step synthesis core-gold/shellceriananomaterialanditscatalysisforhighlyselectivesemihydro genationofalkynes. J.Am. Chem. Soc. 2015, 137, 13452-13455. [CrossRef] [PubMed]

[111] Bera, P.; Hegde, M.S. Characterization and catalytic properties of combustion synthesized $\mathrm{Au} / \mathrm{CeO} 2$ catalyst. Catal. Lett. 2002, 79, 75-81. [CrossRef]

[112] Yang, Y.; Saoud, K.M.; Abdelsayed, V.; Glaspell, G.; Deevi, S.; El-Shall, M.S. Vapor phase synthesis of supported Pd, Au, and unsupported bimetallic nanoparticle catalysts for $\mathrm{CO}$ oxidation. Catal. Commun. 2006, 7, 281-284. [CrossRef]

[113] Potemkin, D.I.; Semitut, E.Y.; Shubin, Y.V.; Plyusnin, P.E.; Snytnikov, P.V.; Makotchenko, E.V.; Osadchii, D.Y.; Svintsitskiy, D.A.; Venyaminov, S.A.; Korenev, S.V.; et al. Silica, alumina and ceria supported AuCu nanoparticles prepared via the decomposition of [Au(en)2]2[Cu(C2O4)2]3·8H2O single-source precursor: Syn thesis, characterizationandcatalyticperformanceinCOPROX. Catal. Today2014, 235,103-111. [CrossRef]

[114] Reina, T.R.; Ivanova, S.; Centeno, M.A.; Odriozola, J.A. Lowtemperature $\mathrm{CO}$ oxidation on multicomponent gold based catalysts. Front. Chem. 2013. [CrossRef]

[115] Haruta, M. Size- and support-dependency in the catalysis of gold. Catal. Today 1997, 36, 153-166. [CrossRef]

[116] Reina, T.R.; Ivanova, S.; Domínguez, M.I.; Centeno, M.A.; Odriozola, J.A. Sub-ambient $\mathrm{CO}$ oxidation over $\mathrm{Au} / \mathrm{MOx} /$ Ce02-Al2O3 (M = Zn or Fe). Appl. Catal. A 2012, 420, 58-66. [CrossRef]

[117] Shuo Zhang, Xiao-Song Li, Bingbing Chen, Xiaobing Zhu, Chuan Shi, and Ai-Min Zhu ${ }^{\dagger}$ Center for Hydrogen Energy and Liquid Fuels, "Laboratory of Plasma Physical Chemistry, Dalian University of technology Dalian. ACS Catal., 2014, 4 (10), pp 3481-3489.

[118] Hyunwoo Ha, Sinmyung Yoon, Kwangjin An, and Hyun You Kim

[ Catalytic CO Oxidation over Au Nanoparticles Supported on $\mathrm{CeO}_{2}$ Nanocrystals: Effect of the $\mathrm{Au}-\mathrm{CeO}_{2}$ Interface. ACS Catal. 2018, 8 (12), pp 11491-11501.

[119] Matteo farnesi camellone, Stefano fabris. Mechanism of CO oxidation on $\mathrm{Au} / \mathrm{CeO} 2$ catalysts: Activity of Substitutional $\mathrm{Au3}+/ \mathrm{Au}+$ Cations and Deactivation of Supported Au+ Adatoms. Journal of the American Chemical Society 131(30):10473-83 - September 2009
[120] M. Haruta, S. Tsubota, T. Kobayashi, H. Kageyama, M.J. Genet, B. Delmon, J. Catal. 144 (1993) 175

[121] S.H. Overbury, L. Ortiz-Soto, H.G. Zhu, B. Lee, M.D. Amiridis, S. Dai, Catal. Lett. 95 (2004) 99.

[122] H.G. Zhu, B. Lee, S. Dai, S.H. Overbury, Langmuir 19 (2003) 3974.

[123] B. Lee, H.G. Zhu, Z.T. Zhang, S.H. Overbury, S. Dai, Micropor. Mesopor. Mater. 70 (2004) 71.

[124] B.P. Block, J.C. Bailar, J. Am. Chem. Soc. 73 (1951) 4722.

[125] D. Guillemot, M. Polisset-Thfoin, J. Fraissard, Catal. Lett. 41 (1996) 143.

[126] R. Zanella, S. Giorgio, C.R. Henry, C. Louis, J. Phys. Chem. B 106 (2002) 7634.

[127] H.G. Zhu, C.D. Liang, W.F. Yan, S.H. Overbury, S. Dai, J. Phys. Chem. B 110 (2006) 10842.

[128] C.-M. Yang, M. Kalwei, F. Schu"th, K.-J. Chao, Appl. Catal. A 254 (2003) 289.

[129] Y.-S. Chi, H.-P. Lin, C.-Y. Mou, Appl. Catal. A 284 (2005) 199.

[130] A.K. Sinha, S. Seelan, T, Akita, S. Tsubota and M. Haruta, Appl. Catal. A: Gen. 240 (2003) 243.

[131] T. Hayashi, K. Tanaka and M. Haruta, J. Catal. 178 (1998) 566.

[132] M. Haruta, B.S. Uphade, S. Tsubota and A. Miyamoto, Res. Chem. Intermed. 24 (1998) 329

[133] T. Akita, K. Tanaka, S. Tsubota, M. Haruta, J. Electron Microsc. 49 (2000) 657.

[134] Y.Z. Yuan, K. Asakura, H.L. Wan, K. Tsai, Y. Iwasawa, Catal. Lett. 42 (1996) 15

[135] N.F. Zheng, G.D. Stucky, J. Am. Chem. Soc. 128 (2006) 14278.

[136] S.-H. Wu, X.-C. Zheng, S.-R. Wang, D.-Z. Han, W.-P. Huang, S.-M. Zhang, Catal. Lett. 96 (2004) 49.

[137] T.V. Choudhary, C. Sivadinarayana, C.C. Chusuei, A.K. Datye, J.P. Fackler, D.W. Goodman, J. Catal. 207 (2002) 247.

[138] Z. Yan, S. Chinta, A.A. Mohamed, J.P. Fackler, D.W. Goodman, Catal. Lett. 111 (2006) 15.

[139] L.D. Menard, F.T. Xu, R.G. Nuzzo, J.C. Yang, J. Catal. 243 (2006) 64

[140] J. Chou, N.R. Franklin, S.-H. Baeck, T.F. Jaramillo, E.W. McFarland, Catal. Lett. 95 (2004) 107.

[141] G. Martra, L. Prati, C. Manfredotti, S. Biella, M. Rossi, S. Coluccia, J. Phys. Chem. B 107 (2003) 5453.

[142] G. Budroni, A. Corma, Angew. Chem. Int. Ed. 45 (2006) 3328.

[143] C.-W. Chiang, A.Q. Wang, C.-Y. Mou, Catal. Today 117 (2006) 220.

[144] R.W.J. Scott, C. Sivadinarayana, O.M. Wilson, Z. Yan, D.W. Goodman, R.M. Crooks, J. Am. Chem. Soc. 127 (2005) 1380

[145] L.S. Ott, R.G. Finke, Coord. Chem. Rev. 251 (2007) 1075.

[146] Z. Ma, F. Zaera, Surf. Sci. Rep. 61 (2006) 229.

[147] R. Zanella, S. Giorgio, C.R. Henry, C. Louis, J. Phys. Chem. B 106 (2002) 7634

[148] Q. Xu, K.C.C. Kharas, A.K. Datye, Catal. Lett. 85 (2003)229.

[149] A. Wolf, F. Schu"th, Appl. Catal. A 226 (2002) 1

[150] F. Moreau, G.C. Bond, Appl. Catal. A 302 (2006) 110.

[151] Y.Z. Yuan, K. Asakura, A.P. Kozlova, H.L. Wan, K.R. Tsai, Y. Iwasawa, Catal. Today 44 (1998) 333.

[152] M.A. Sanchez-Castillo, C. Couto, W.B. Kim, J.A. Dumesic, Angew. Chem. Int. Ed. 43 (2004) 1140.

[153] S.D. Ebbesena, B.L. Mojeta, L. Lefferts, J. Catal. 246 (2007) 66.

[154] Shelef, M.; Graham, G.W. Why rhodium in automotive threeway catalysts? Catal. Rev. 1994, 36, 433-457. 
[155] Sinha, A.K.; Sindhu, S.; Susumu, T.; Masatake, H. A threedimensional mesoporous titanosilicate support for gold nanoparticles: Vapor-phase epoxidation of propene with high conversion. Angew. Chem. Int. Ed. 2004, 43, 1546-1548

[156] Taylor, B.; Lauterbach, J.; Delgass, W.N. Gas-phase epoxidation of propylene over small gold ensembles on TS-1. Appl. Catal. A 2005, 291, 188-198.

[157] Valden, M.; Lai, X.; Goodman, D.W. Onset of catalytic activity of gold clusters on titania with the appearance of nonmetallic properties. Science 1998, 281, 1647-1650.

[158] M.S. Chen, D.W. Goodman, Science 306 (2004) 252.

[159] 159. Sobolev Vladimir, Konstantin koltunov. Catalytic epoxidation of propylene with $\mathrm{CO} / 02$ over Au/TiO2. Applied Catalysis A General 476:197-203 · April 2014

[160] Ji, J., Turner, C. H., Lei, Y., Lu, Z., Mechanistic Insights into the Direct Propylene Epoxidation over Au/TiO2/SiO2. 2018 AIChE Annual Meeting.

[161] Carmela Aprile a, Avelino Corma a, ${ }^{\star}$, Marcelo E. Domine a, Hermenegildo Garcia a, Chris Mitchell b. A Cascade Aerobic Epoxidation Of Alkenes Over Au/Ceo2 And Ti-Mesoporous Material By “In Situ” Formed Peroxides, Journal of Catalysis 264 (2009) 44-53.

[162] S. Carretin, P. Concepcion, J.M. Lopez-Nieto, V.F. Puntes, A. Corma, Angew.Chem., Int. Ed. 43 (19) (2004) 2538.

[163] A. Corma, M. Domine, J. Gaona, J.L. Jordá, M.T. Navarro, J. Pérez-Pariente, F. Rey,B. McCulloch, L. Nemeth, J. Tsuji, Chem. Commun. (1998) 2211.

[164] A. Corma, J.L. Jordá, M.T. Navarro, J. Pérez-Pariente, F. Rey, J. Tsuji, Stud. Surf.Sci. Catal. 129 (2000) 169.

[165] J. Tsuji, J. Yamamoto, A. Corma, F. Rey, US Patent 6211 388, 1998, assigned to Sumitomo Chemical Company, Ltd.

[166] Shilong Chen, UO Liangfeng, Zhiquan Jiang, Weixin Huang. Size-Dependent Reaction Pathways of Low-Temperature $\mathrm{CO}$ Oxidation on $\mathrm{Au} / \mathrm{CeO} 2$ Catalysts. ACS Catalysis 5(3):150203111937007 · February 2015

[167] A.K. Sinhaa, S. Seelana, S. Tsubotaa, and M. Harutab, *. Catalysis By Gold Nanoparticles: Epoxidation Of Propene. Plenum Publishing Corporation. Vol. 29, Nos. 3-4, June 2004.

[168] B.S. Uphade, T. Akita, T. Nakamura and M. Haruta, J. Catal. 209 (2002) 331.

[169] A.K. Sinha, S. Seelan, S. Tsubota and M. Haruta, Stud. Surf. Sci. Catal. [Eds: E.M. Gaigneaux, R. Avello, F. Testa, and G. Giordano] 143 (2002) 167.

[170] A.K. Sinha, T. Akita, S. Tsubota and M. Haruta, Stud. Surf. Sci. Catal. [Eds; R. Aielloe, E. Gaigneaux, D.E. De Vos, P. Grange, P.A. Jacobs, J.A. Martens, P. Ruiz, and G. Poncelet], 142 (2002) 611.

[171] M.P. Kapoor, A.K. Sinha, S. Seelan, S. Inagaki, S. Tsubota, H. Yoshida and M. Haruta, Chem. Commun. (2002) 2902.

[172] C. Qi, T. Akita, M. Okumura and M. Haruta, Appl. Catal. 218 (2001) 81

[173] T. Hayashi, K. Tanaka and M. Haruta, Shokubai 37 (1995) 72

[174] A.K. Sinha, S. Seelan, T, Akita, S. Tsubota and M. Haruta, Appl. Catal. A: Gen. 240 (2003) 243.

[175] T. Hayashi, K. Tanaka and M. Haruta, J. Catal. 178 (1998) 566.

[176] M. Haruta, B.S. Uphade, S. Tsubota and A. Miyamoto, Res. Chem. Intermed. 24 (1998) 329

[177] T. Akita, K. Tanaka, S. Tsubota, M. Haruta, J. Electron Microsc. $49(2000) 657$.
[178] B.S. Uphade, T. Akita, T. Nakamura and M. Haruta, J. Catal. 209 (2002) 331

[179] A.K. Sinha, S. Seelan, S. Tsubota and M. Haruta, Stud. Surf. Sci. Catal. [Eds: E.M. Gaigneaux, R. Avello, F. Testa, and G. Giordano] 143 (2002) 167.

[180] B.S. Uphade, S. Tsubota, T. Hayashi and M. Haruta, Chem. Lett. (1998) 1277.

[181] B.S. Uphade, M. Okumura, S. Tsubota and M. Haruta, Appl. Catal. A: Gen. 190 (2000) 43.

[182] Jieli He, Qingge Zhai, Qinghong Zhang, Weiping Deng, Ye Wang. Active site and reaction mechanism for the epoxidation of propylene by oxygen over $\mathrm{CuOx} / \mathrm{SiO}_{2}$ catalysts with and without $\mathrm{Cs}^{+}$modification. Journal of Catalysis. Volume 299, March 2013, Pages 53-66

[183] H. Sakurai *, M. Haruta. Synergism In Methanol Synthesis From Carbon Dioxide Over Gold Catalysts Supported On Metal Oxides. Catalysis Today 29 (1996) 361-365

[184] M. Haruta, S. Tsubota, T. Kobayashi, H. Kageyama, M.J. Genet and B. Delmon, J. Catal., 175 (1993) 144.

[185] H. Sakurai *, M. Haruta. Synergism in Methanol Synthesis from Carbon Dioxide over Gold Catalysts Supported On Metal Oxides. Catalysis Today 29 (1996) 361-365).

[186] E.A Shaw, A.P Walker, T. Rayment, R.M. Lambert. J. Catalysis. Vol.134, April 1992, pages 747-750

[187] Boucher M, Yi N, Zugic B, Si R, Saltsburg H, FlytzaniStephanopoulos M. Catalysis and reaction engineering division. ALChE annual conference 2010.

[188] P.Bazin, S.Thomas, O. Marie, M. Daturi. New insights into the methanol oxidation mechanism over $\mathrm{Au} / \mathrm{CeO}_{2}$ catalyst through complementary kinetic and FTIR operando SSITKA approaches. Catalysis Today Volume 182, Issue 1, 17 March 2012, Pages 3-11

[189] (T. Li, S.J. Wang*, C.S. Yu, Y.C. Ma, K.L. Li, L.W. Lin. Direct Conversion Of Methane To Methanol Over Nano-[Au/Sio2] In [Bmim]Cl lonic Liquid, Applied Catalysis A: General 398 (2011) 150-154). 